\title{
Noninvasive Bioluminescence Imaging of $\alpha$-Synuclein Oligomerization in Mouse Brain Using Split Firefly Luciferase Reporters
}

\author{
Sarah-Ann Aelvoet, ${ }^{1}$ Abdelilah Ibrahimi, ${ }^{2}$ Francesca Macchi, ${ }^{1}$ Rik Gijsbers, ${ }^{2,3}$ Chris Van den Haute, ${ }^{1,3}$ Zeger Debyser, ${ }^{2}$ \\ and $\odot$ Veerle Baekelandt ${ }^{1}$ \\ ${ }^{1}$ KU Leuven, Laboratory for Neurobiology and Gene Therapy, Department of Neurosciences, 3000 Leuven, Flanders, Belgium, ${ }^{2} \mathrm{KU}$ Leuven, Laboratory for \\ Molecular Virology and Gene Therapy, Department of Pharmaceutical and Pharmacological Sciences, 3000 Leuven, Flanders, Belgium, and ${ }^{3}$ KU Leuven, \\ Leuven Viral Vector Core, 3000 Leuven, Flanders, Belgium
}

\begin{abstract}
Alpha-synuclein $(\alpha \mathrm{SYN})$ aggregation plays a pivotal role in the pathogenesis of Parkinson's disease and other synucleinopathies. In this multistep process, oligomerization of $\alpha \mathrm{SYN}$ monomers is the first step in the formation of fibrils and intracytoplasmic inclusions. Although $\alpha S Y N$ oligomers are generally considered to be the culprit of these diseases, the methodology currently available to follow-up oligomerization in cells and in brain is inadequate. We developed a split firefly luciferase complementation system to visualize oligomerization of viral vector-encoded $\alpha \mathrm{SYN}$ fusion proteins. $\alpha \mathrm{SYN}$ oligomerization resulted in successful luciferase complementation in cell culture and in mouse brain. Oligomerization of $\alpha \mathrm{SYN}$ was monitored noninvasively with bioluminescence imaging in the mouse striatum and substantia nigra up to 8 months after injection. Moreover, the visualized $\alpha$ SYN oligomers retained their toxic and aggregation properties in both model systems. Next, the effect of two small molecules, FK506 and (-)-epigallocatechin-3-gallate (EGCG), known to inhibit $\alpha$ SYN fibril formation, was investigated. FK506 inhibited the observed $\alpha$ SYN oligomerization both in cell culture and in mouse brain. In conclusion, the split firefly luciferase- $\alpha \mathrm{SYN}$ complementation assay will increase our insight in the role of $\alpha \mathrm{SYN}$ oligomers in synucleinopathies and opens new opportunities to evaluate potential $\alpha$ SYN-based neuroprotective therapies.
\end{abstract}

Key words: alpha-synuclein; imaging; mice; noninvasive; oligomerization; split-Fluc

\section{Introduction}

Over the last 15 years, it has become clear that the aggregation of $\alpha$-synuclein $(\alpha \mathrm{SYN})$ is causally linked to Parkinson's disease (PD) (reviewed by Deleersnijder et al., 2013). A fibrillar form of $\alpha$ SYN occurs in Lewy bodies (LBs) and Lewy neurites, pathological hallmarks of PD, which are also observed in multiple system atrophy and dementia with LBs, and are together referred to as synucleinopathies (Spillantini et al., 1997; Halliday et al., 2011). $\alpha \mathrm{SYN}$ is generally thought to exist as a small intrinsically disor-

Received Nov. 25, 2013; revised 0ct. 22, 2014; accepted 0ct. 24, 2014.

Author contributions: S.-A.A., A.I., C.V.d.H., Z.D., and V.B. designed research; S.-A.A., A.I., and F.M. performed research; S.-A.A., A.I., F.M., R.G., Z.D., and V.B. analyzed data; S.-A.A., A.I., R.G., Z.D., and V.B. wrote the paper.

This work was supported by the IWT Vlaanderen (IWT SB0/80020 Neuro-TARGET and IWT SB0/130065 MIRIAD), the FWO Vlaanderen (G.0768.10), the KU Leuven (0T/08/052A, IMIR PF/10/017), and the FP7 RTD projects MEFOPA (HEALTH-2009-241791) and INMiND (HEALTH-F2-2011-278850). S.-A.A. was supported by the Institute for the Promotion of Innovation through Science and Technology in Flanders (IWT Vlaanderen). The authors thank Sylvie De Swaef, Valérie Coessens, Caroline van Heijningen, Joris Van Asselberghs, Irina Thiry, Nam-Joo Van der Veken, Stephanie Deman, Wim Werckx, and Diana Piol for excellent technical assistance; the Leuven Viral Vector Core managed by Dr. Annelies Michiels for the construction and production of LV and AAV vectors; and Prof. Dr. Johan Hofkens and Charlotte David (Molecular Imaging and Photonics, KU Leuven) for the use of the confocal laser-scanning microscope.

The authors declare no competing financial interests.

Correspondence should be addressed to Dr. Veerle Baekelandt, Laboratory for Neurobiology and Gene Therapy, Department of Neurosciences, KU Leuven, Kapucijnenvoer 33, VCTB +5 bus 7001, B-3000 Leuven, Belgium. E-mail: veerle.baekelandt@med.kuleuven.be.

DOI:10.1523/JNEUROSCI.4933-13.2014

Copyright $\odot 2014$ the authors $\quad 0270-6474 / 14 / 3416518-15 \$ 15.00 / 0$ dered protein, without stable tertiary structure in solution that adopts an $\alpha$-helical structure when bound to membranes (Davidson et al., 1998). Recent literature has suggested that $\alpha \mathrm{SYN}$ may adopt a stable tetrameric conformation under physiological conditions, but these findings remain under debate (Bartels et al., 2011; Wang et al., 2011; Binolfi et al., 2012; Fauvet et al., 2012; Burré et al., 2013). During the aggregation process, disordered monomeric or folded tetrameric $\alpha \mathrm{SYN}$ species assemble to form soluble oligomers that, in turn, mature into insoluble fibrils. The current prevalent hypothesis pinpoints the oligomers as the toxic $\alpha$ SYN species (Sharon et al., 2003; Karpinar et al., 2009; Paleologou et al., 2009; Winner et al., 2011; Colla et al., 2012; Kalia et al., 2013). Conversion into insoluble fibrils might protect the cell from these toxic $\alpha$ SYN oligomers (Ross and Poirier, 2004).

Although inhibition of $\alpha \mathrm{SYN}$ oligomer formation is a logical therapeutic strategy, the available tools to detect $\alpha \mathrm{SYN}$ oligomers in cell culture are inadequate. Moreover, misfolded $\alpha \mathrm{SYN}$ species in the brain of rodent PD models can only be detected and thus studied postmortem. In addition, the majority of postmortem studies have focused on $\alpha$ SYN fibrils rather than on $\alpha$ SYN oligomers. A bioluminescence-based protein fragment complementation assay (PCA) is a method to visualize protein-protein interactions whereby luciferase is split and its N-terminal and C-terminal parts are fused to either one of two interacting proteins (Paulmurugan et al., 2002). A bioluminescent PCA based on 
split Gaussia luciferase (Gluc) has already been developed to detect $\alpha$ SYN oligomers in cell culture (Putcha et al., 2010; Danzer et al., 2011, 2012). However, the latter system cannot be translated to living animals because the blue emission light is highly absorbed by surrounding tissue (Zhao et al., 2005) and the Gluc substrate coelenterazine does not efficiently pass an intact bloodbrain barrier (BBB) (Pichler et al., 2004).

We and others previously demonstrated that the firefly luciferase (Fluc) is an ideal reporter for noninvasive bioluminescence imaging (BLI) in rodent brain (Deroose et al., 2006, 2009; Massoud et al., 2008; Reumers et al., 2008; Heeman et al., 2011; Vandeputte et al., 2014). Here, we engineered and characterized a bioluminescent PCA based on a split-Fluc reporter system to monitor $\alpha \mathrm{SYN}$ oligomerization, both in cell culture and in the brain of living animals. Using this approach, we evaluated the effect of the small molecules FK506 and (-)-epigallocatechin-3gallate (EGCG) on the $\alpha \mathrm{SYN}$ oligomerization process in cells and in the mouse brain.

\section{Materials and Methods}

Viral vector construction and production. Overexpression of the different genes of interest in cell culture was achieved via lentiviral (LV) vectors, in which gene expression is controlled by the cytomegalovirus immediate early (CMVie) promoter. First, FlucN-FKBP12-rapamycin binding (FRB) and FKBP12-FlucC were cloned from pcDNA-FlucN-FRB and pcDNA-FKBP12-FlucC (Paulmurugan and Gambhir, 2007) into the pCHMWS transfer plasmid (Baekelandt et al., 2002). Next, FRB and FKBP12 coding sequences were replaced by $\alpha$ SYN or eGFP. Highly concentrated human immunodeficiency virus type 1 (HIV-1)-derived LV vectors were produced as described previously, based on the triple transfection method with a transfer plasmid, an envelope plasmid encoding glycoprotein $G$ of vesicular stomatitis virus and a second-generation packaging plasmid (Ibrahimi et al., 2009). The resulting lentiviral vectors are referred to as FlucN-FRB LV, FKBP12-FlucC LV, FlucN- $\alpha$ SYN LV, $\alpha$ SYN-FlucC LV, and eGFP-FlucC LV, respectively. Viral titers were determined using p24 ELISA (HIV-1 p24 ELISA kit, PerkinElmer, ng p24/ $\mathrm{ml})$.

Overexpression of genes of interest in the mouse brain was achieved with recombinant adeno-associated viral (AAV) vectors, in which gene expression is controlled by the CMVie promoter. The different expression cassettes were cloned from pCHMWS transfer plasmids into the pAAV transfer plasmid (Van der Perren et al., 2011). Highly concentrated AAV vectors of serotype $2 / 7$ were produced as described previously, based on the triple transfection method with a transfer plasmid, the AAV serotype 7 plasmid (pAAV7), and the AAV helper plasmid (Van der Perren et al., 2011). Viral titers were determined as DNase resistant genome copies (GCs) using a standard qPCR. Genome copies obtained for the different productions ranged between $3 \times 10^{11}$ and $7 \times 10^{11}$ $\mathrm{GC} / \mathrm{ml}$. All experiments with $\mathrm{LV}$ and AAV vectors were performed under biosafety level 2 conditions.

Cell culture and LV transduction. Human dopaminergic neuroblastoma SHSY5Y cells were maintained in DMEM (Invitrogen) supplemented with $15 \%$ heat-inactivated fetal calf serum (Harlan Sera-Lab, International Medical), $1 \%$ nonessential amino acids (Invitrogen), and $50 \mu \mathrm{g} / \mathrm{ml}$ gentamycin (Invitrogen), referred to as DMEM complete. Cells were maintained at $37^{\circ} \mathrm{C}$ and $5 \% \mathrm{CO}_{2}$ in a humidified atmosphere and were mycoplasma free. For the generation of stable overexpression cell lines, 150,000 SHSY5Y cells were plated in a 24 -well plate. The next day, cells were transduced with either one or two LV vectors, normalized for vector titers $(\mathrm{p} 24 / \mathrm{ml})$, for $24 \mathrm{~h}$, after which the vector-containing medium was replaced by DMEM complete. After $5 \mathrm{~d}$ in culture, cells were controlled for overexpression of specific proteins via Western blot.

Luciferase activity assay. Stable overexpression cell lines were plated out at a density of 40,000 cells/well in a 96-well plate. The next day, medium was replaced with fresh medium, or medium supplemented with $10 \mathrm{~nm}$ rapamycin (Sigma-Aldrich) and/or $1 \mu \mathrm{M}$ FK506 (SigmaAldrich). The next day, the cells were washed with PBS and subsequently lysed with $70 \mu \mathrm{l}$ of lysis buffer containing $50 \mathrm{~mm}$ Tris, pH 7.5, $200 \mathrm{~mm}$ $\mathrm{NaCl}, 0.2 \%$ Nonidet P-40 (NP-40), 1 mm PMSF, and 10\% glycerol. After a freeze-thaw cycle, the lysate was centrifuged for $5 \mathrm{~min}$ at $1500 \times \mathrm{g}$. A total of $5 \mu$ l of the supernatant was assayed for luciferase activity after the addition of $25 \mu \mathrm{l}$ of ONE-Glo Luciferase Reagent (Promega). The produced light was measured at an integration time of $1 \mathrm{~s}$ with a GloMax luminometer (Promega). Data were normalized to the total protein concentration, which was determined by the bicinchoninic acid assay (Pierce Biotechnology) and are presented as relative light units per microgram of protein.

Western blot. Three days after transduction, cells were washed twice with PBS and lysed with $100 \mu \mathrm{l}$ 1\% SDS solution, supplemented with protease cocktail inhibitor (Roche Diagnostics). Cell extracts were boiled for $5 \mathrm{~min}$ and homogenized by 10 passages through a 30-gauge insulin syringe followed by a final boiling step of $5 \mathrm{~min} ; 25 \mu \mathrm{g}$ of total protein, measured by the bicinchoninic acid assay, was separated on a $10 \%$ BisTris gel (Novex) and electroblotted for $1 \mathrm{~h}$ at $50 \mathrm{~V}$ onto PVDF membranes (Bio-Rad). Membranes were blocked with $5 \%$ milk powder in PBS supplemented with $0.1 \%$ Tween 20 , and incubated with primary antibodies goat anti-Fluc (1:3000, Promega) or mouse anti- $\alpha$-tubulin (1:1000, Sigma). Detection was performed after incubation with appropriate HRP-conjugated secondary antibodies (Dako) using chemiluminescence $\left(\mathrm{ECL}^{+}\right.$-kit, Pierce).

Immunocytochemistry. Stable overexpression cell lines were generated as described above, by cotransduction with FlucN- $\alpha$ SYN LV and $\alpha$ SYNFlucC LV. Cells transduced with wild-type (WT) $\alpha$ SYN LV served as positive controls; 70,000 cells were plated in gelatin-coated 8-well chamber slides (Thermo Fisher Scientific). The next day, $\alpha \mathrm{SYN}$ aggregation was induced by exposing the cells to oxidative stress (Ostrerova-Golts et al., 2000; Gerard et al., 2010). The cells were exposed for $72 \mathrm{~h}$ to $100 \mu \mathrm{M}$ $\mathrm{H}_{2} \mathrm{O}_{2}$ and $5 \mathrm{~mm}$ freshly prepared $\mathrm{FeCl}_{2}$ in DMEM complete, filtered through a $0.20 \mu \mathrm{m}$ filter (Corning). Control cells were incubated with fresh DMEM complete. After $3 \mathrm{~d}$, the cells were washed with PBS and fixed with $4 \%$ formaldehyde for $15 \mathrm{~min}$. For the detection of oligomeric or total $\alpha \mathrm{SYN}$, the cells were washed for 10 min with PBS $0.1 \%$ Triton (PBS-T). After a $1 \mathrm{~h}$ blocking step with donkey serum (Jackson ImmunoResearch Laboratories), cells were incubated overnight with oligomerspecific antibody (rabbit polyclonal antibody A11, 1:400, Invitrogen) or rabbit anti- $\alpha$ SYN (AB5038, 1:200, Millipore). After 3 washing steps with PBS for $5 \mathrm{~min}$, the cells were incubated for $2 \mathrm{~h}$ with AlexaFluor-488conjugated donkey anti-rabbit antibody (1:500, Invitrogen) and washed again 3 times with PBS. Finally, the cells were mounted using Mowiol (Sigma-Aldrich) containing DAPI (1:10.000, Invitrogen). Cells were analyzed with a confocal microscope (FV1000, Olympus) with a $488 \mathrm{~nm}$ argon ion laser. Brightness, contrast, and background were adjusted equally per corresponding staining using the Fluoview software. High content analysis of $\alpha \mathrm{SYN}$ aggregation was performed as described previously; fibrillar $\alpha \mathrm{SYN}$ aggregates were detected via a Thioflavin-S (Thio-S) staining (Gerard et al., 2010).

Biochemical analysis of $\alpha S Y N$ oligomers in cell culture. To detect and discriminate different sizes of oligomers, a cross-linking protocol was adapted with some minor modifications (Dettmer et al., 2013). Briefly, $2,000,000$ cells either expressing WT $\alpha$ SYN or FlucN- $\alpha \mathrm{SYN}+\alpha \mathrm{SYN}-$ FlucC were plated out. The next day, cells were collected by scraping, washed with PBS, and resuspended in $200 \mu \mathrm{l}$ PBS with $1 \times$ Complete Protease Inhibitor Mixture, EDTA-free (Roche Diagnostics). Immediately before use, a $50 \mathrm{~mm}$ stock of the cross-linker disuccinimidyl glutarate (DSG) was prepared in DMSO. DSG was applied on intact cells because it was previously shown that $\alpha \mathrm{SYN}$ oligomers are sensitive to cell lysis (Dettmer et al., 2013). The samples were incubated with $1 \mathrm{~mm}$ DSG or DMSO for $30 \mathrm{~min}$ at $37^{\circ} \mathrm{C}$ in a shaking incubator. The cross-linking reaction was quenched by addition of $1 \mathrm{M}$ Tris, $\mathrm{pH} 7.5$, to $50 \mathrm{~mm}$ final concentration and incubated for $15 \mathrm{~min}$ at room temperature. Next, samples were lysed by $15 \mathrm{~s}$ sonication. Finally, the samples were ultracentrifuged (Optima TLX, Beckman) for $30 \mathrm{~min}$ at 200,000 $\times g$ to recover the cytosolic fraction from the supernatant. A total of $10 \mu \mathrm{g}$ of protein was loaded on $4 \%-12 \%$ Bis-Tris gels (for WT $\alpha \mathrm{SYN}$ ) or $3 \%-8 \%$ Trisacetate gels (for Fluc-tagged $\alpha \mathrm{SYN}$ ) (Novex). After electroblotting, the PVDF membranes were incubated for $30 \mathrm{~min}$ in $0.4 \%$ PFA and rinsed 
twice with PBS (Lee and Kamitani, 2011; Dettmer et al., 2013; Newman et al., 2013). Blocking and immunodetection were performed as described above. The effectiveness of cross-linking was analyzed by immunoblotting with the monoclonal antibody $15 \mathrm{G} 7$, which specifically detects human $\alpha$ SYN (rat anti-human $\alpha$ SYN 15G7, 1:100, Enzo Life Sciences). Other antibodies that were used are rabbit anti-DJ1 (1:1000, Covance), goat anti-Fluc (1/3000, Promega), mouse anti- $\beta$-actin (1:1000, Sigma), and goat anti- $\beta$-actin (1:1000, Santa Cruz Biotechnology).

Stereotactic injections. All animal experiments were performed in accordance with the European Communities Council Directive of November 24, 1986 (86/609/EEC) and approved by the Bioethical Committee of the KU Leuven (Belgium). Adult male and female 12- to 15-week-old albino $C 57 B L / 6-$ Tyr $^{\mathrm{c}-2 \mathrm{~J}} / \mathrm{J}$ mice (stock \#000058, The Jackson Laboratory) were housed under a $12 \mathrm{~h}$ light/12 h dark cycle with free access to food and water. Anesthesia was induced by intraperitoneal injection of a mixture of ketamine $(75 \mathrm{mg} / \mathrm{kg}$ Ketalar, Pfizer) and medetomidine $(1 \mathrm{mg} / \mathrm{kg}$ Domitor, Pfizer). The mice were placed in a stereotactic head frame (Stoelting). A midline incision of the skin was made and a small hole drilled in the skull at the appropriate location, using bregma as reference. Coordinates to target mouse striatum were anteroposterior $0.5 \mathrm{~mm}$, mediolateral $-2.0 \mathrm{~mm}$ relative to bregma, and dorsoventral -3.0 to $2.0 \mathrm{~mm}$ from the dural surface. Coordinates for mouse substantia nigra (SN) were anteroposterior $-3.1 \mathrm{~mm}$, mediolateral $-1.2 \mathrm{~mm}$, and dorsoventral $-4.0 \mathrm{~mm}$. The different AAV vectors were normalized by titer and volume, resulting in injection of an equal amount of GC per vector and 2 $\mu \mathrm{l}$ (in the striatum and SN) or $4 \mu \mathrm{l}$ (in the striatum) of a mixture of 2 vectors was injected. The vectors were injected at a rate of $0.25 \mu \mathrm{l} / \mathrm{min}$ with a 30 -gauge needle (VWR International) on a $10 \mu$ l syringe (Hamilton). After the injection, the needle was left in place for an additional 5 min to allow diffusion before being slowly withdrawn from the brain. Anesthesia was reversed with an intraperitoneal injection of atipamezol $(0.5 \mathrm{mg} / \mathrm{kg}$ Antisedan, Pfizer). The number of animals is indicated in the figure legends.

In vivo bioluminescence imaging. The mice were imaged in an IVIS 100 system (PerkinElmer). Anesthesia was performed in an induction chamber with $2 \%$ isoflurane (Halocarbon Products) in 100\% oxygen at a flow rate of $1 \mathrm{~L} / \mathrm{min}$ and maintained in the IVIS with a $1.5 \%$ mixture at 0.5 $\mathrm{L} / \mathrm{min}$. Because fur negatively influences BLI signals (Deroose et al., 2006), the heads of the mice were shaved before each imaging session; 126 $\mathrm{mg} / \mathrm{kg}$ D-luciferin (Promega) dissolved in PBS $(15 \mathrm{mg} / \mathrm{ml})$ was injected intravenously. Immediately after injection, the mice were placed in the prone position in the IVIS and consecutive $1 \mathrm{~min}$ frames were acquired until the maximum signal, between 1 and 5 min after luciferin injection, was reached. The data are reported as the photon flux $(\mathrm{p} / \mathrm{s})$ from a 1.5 $\mathrm{cm}^{2}$ circular region of interest around the head.

Perfusion and immunohistochemistry. Mice were deeply anesthetized by intraperitoneal injection of pentobarbital $(60 \mathrm{mg} / \mathrm{kg}$, Nembutal, Ceva Santé Animale) and perfused transcardially with saline followed by icecold $4 \%$ PFA in PBS. After fixation overnight, $50-\mu \mathrm{m}$-thick coronal brain sections were made with a vibratome (HM 650V, Microm). Immunohistochemistry was performed on every fifth section throughout the whole striatum or SN. Free-floating sections were pretreated with $3 \%$ hydrogen peroxide (Chem-Lab) in PBS-T for 10 min and incubated overnight with rabbit anti-tyrosine hydroxylase (TH, 1:1000, Millipore) or rat antidopamine active transporter (1:1000, Millipore) in PBS-T with 10\% normal goat or swine serum (Dako). Appropriate biotinylated secondary antibodies were used (1:300, Dako), followed by incubation with streptavidin-HRP complex (1:1000, Dako). For the detection of (phosphorylated) $\alpha \mathrm{SYN}$, stainings were performed in fresh TBS and sections were washed with TBS with $0.1 \%$ Triton X-100 (TBS-T). Sections were pretreated for 10 min with $10 \%$ methanol and $3 \%$ hydrogen peroxide in TBS, followed by $1 \mathrm{~h}$ incubation in $10 \%$ swine serum. Next, they were incubated overnight with rabbit anti- $\alpha \mathrm{SYN}$ (AB5038, 1:5000, Millipore) or mouse antibodies against $\alpha \mathrm{SYN}$ phosphorylated at position serine 129 (S129p $\alpha \mathrm{SYN}$ ) (11A5, 1:5000, Elan Pharmaceuticals) (Anderson et al., 2006). Appropriate biotinylated secondary antibodies were used (1:600, Dako), followed by incubation with streptavidin-HRP complex in TBS-T (1:1000, Dako). Immunoreactivity was visualized using DAB $(0.4 \mathrm{mg} / \mathrm{ml}$, Sigma-Aldrich) or Vector SG (Vector Laboratories) as a chromogen.
After a dehydration series, stained sections were mounted with DPX (Sigma-Aldrich) and visualized with a light microscope (Leica Microsystems).

For fluorescent double stainings, sections were washed in PBS and incubated overnight with mouse anti- $\alpha$ SYN (LB509, 1:100, Invitrogen) or rat anti- $\alpha$ SYN (15G7, 1:200, Enzo Life Sciences) and chicken antiubiquitin (1:200, Sigma) or goat anti-DARPP32 (dopamine- and cAMPregulated phosphoprotein of $32 \mathrm{kDa}, 1: 50$, Santa Cruz Biotechnology) or chicken anti-TH (1:500, Aves Laboratories) and rabbit anti-neuronal nuclear antigen (NeuN) (1:1000, Millipore) in PBS-T with 10\% donkey serum. After 3 washing steps with PBS-T, sections were incubated for $2 \mathrm{~h}$ with appropriate Alexa488-, Alexa555-, and Alexa633-labeled secondary antibodies. Next, the sections were washed in PBS-T and mounted with Mowiol. Fluorescence was detected with a confocal microscope (FV1000, Olympus) with a 488 , a 559 , and a $633 \mathrm{~nm}$ laser.

For the detection of fibrillar $\alpha \mathrm{SYN}$ species, free-floating sections were washed 2 times for $1 \mathrm{~min}$ in AD. Next, they were incubated for $5 \mathrm{~min}$ in freshly prepared 1\% Thio-S (Sigma-Aldrich) in distilled water, followed by 5 min of incubation in 70\% ethanol. After 3 brief washing steps with $\mathrm{AD}$, sections were mounted with Mowiol. Fibrils were detected with a $488 \mathrm{~nm}$ laser.

Biochemical analysis of $\alpha S Y N$ oligomers in mouse brain. For the analysis of $\alpha \mathrm{SYN}$ oligomers in mouse brain, the right striatum of two mice per group was isolated and homogenized in $200 \mu \mathrm{l}$ PBS with $1 \times$ Complete Protease Inhibitor Mixture, EDTA-free. The brain homogenates were then divided in $100 \mu \mathrm{l}$ for cross-linker treatment and $100 \mu \mathrm{l}$ for DMSO treatment. Cross-linking and immunodetection were performed as described for cell culture experiments.

Stereological quantification. To quantify the degree of dopaminergic degeneration in the $\mathrm{SN}$, the total number of TH-positive cells in the injected and contralateral SN was measured with an unbiased stereological counting method using the optical fractionator principle in a computerized system, as described previously (StereoInvestigator, MicroBright-Field) (Oliveras-Salvá et al., 2013). Every fifth section was analyzed, with a total of 5 sections for each animal. The volume of THimmunoreactive fibers in the striatum was determined by stereological volume measurements based on the Cavalieri method as described previously (Baekelandt et al., 2002; Vercammen et al., 2006). Every fifth section was analyzed, with a total of 6 sections for each animal. The values for cell loss in the $\mathrm{SN}$ and fiber loss in the striatum are expressed relative to the control hemisphere.

Evaluation of inhibition of $\alpha$ SYN oligomerization by FK506 and EGCG. To evaluate the effect of FK506 and EGCG on $\alpha$ SYN oligomerization in cell culture, a stable overexpression cell line was generated as described above, by cotransduction with FlucN- $\alpha$ SYN LV and $\alpha$ SYN-FlucC LV for $24 \mathrm{~h}$, after which the vector-containing medium was replaced by DMEM complete. To verify whether FK506 and EGCG influence luciferase activity, a cell line overexpressing full-length Fluc was generated in the same way by transduction with eGFP-T2A-Fluc LV. After $5 \mathrm{~d}$ in culture, overexpression of specific proteins was verified via Western blot. A total of 30,000 cells were plated in a 96-well plate. The next day, medium was replaced with fresh DMEM complete complemented with either $10 \mu \mathrm{M}$ FK506 (Sigma-Aldrich), $25 \mu \mathrm{M}$ EGCG (Sigma-Aldrich), or DMSO (Sigma-Aldrich), resulting in $0.1 \%$ DMSO in all conditions. Luciferase activity was determined $24 \mathrm{~h}$ after addition of the compounds. The luciferase activity from cells expressing FlucN- $\alpha \mathrm{SYN}+\alpha \mathrm{SYN}$-FlucC was normalized to that of cells expressing eGFP-T2A-Fluc.

To assess the effect of FK506 and EGCG on $\alpha$ SYN oligomerization in mouse brain, 10-week-old female albino FVB/N mice (Janvier) were stereotactically injected as described above. The experimental group was injected with $2 \mu$ l of a 1:1 mixture of FlucN- $\alpha$ SYN and $\alpha$ SYN-FlucC AAV vectors in the striatum. A control group was injected with $2 \mu \mathrm{l}$ of eGFPT2A-Fluc AAV. Daily intraperitoneal injections with freshly prepared compounds were initiated $1 \mathrm{~d}$ after stereotactic surgery and continued for 28 d. FK506 (Cayman Chemicals) was dissolved in 10\% ethanol in $0.9 \%$ sterile saline containing $1 \%$ Tween 80 , and a final dose of $5 \mathrm{mg} / \mathrm{kg} / \mathrm{d}$ was administered (Hong et al., 2010). EGCG (Cayman Chemicals) was dissolved in $0.9 \%$ sterile saline, and a final dose of $20 \mathrm{mg} / \mathrm{kg} / \mathrm{d}$ was administered (Rezai-Zadeh et al., 2005; Wang et al., 2012). A similar 


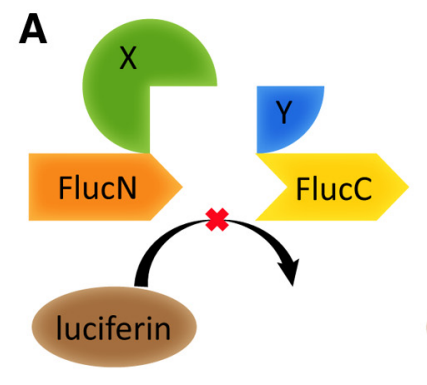

C

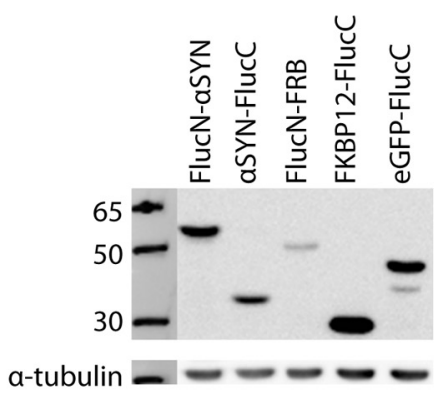

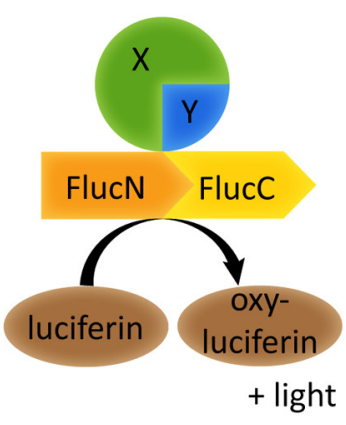

B

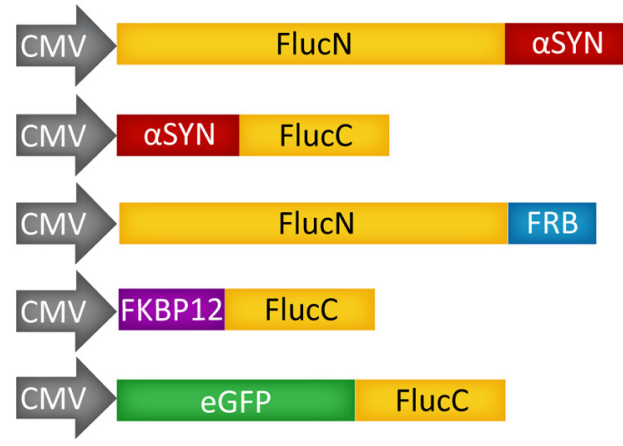

D

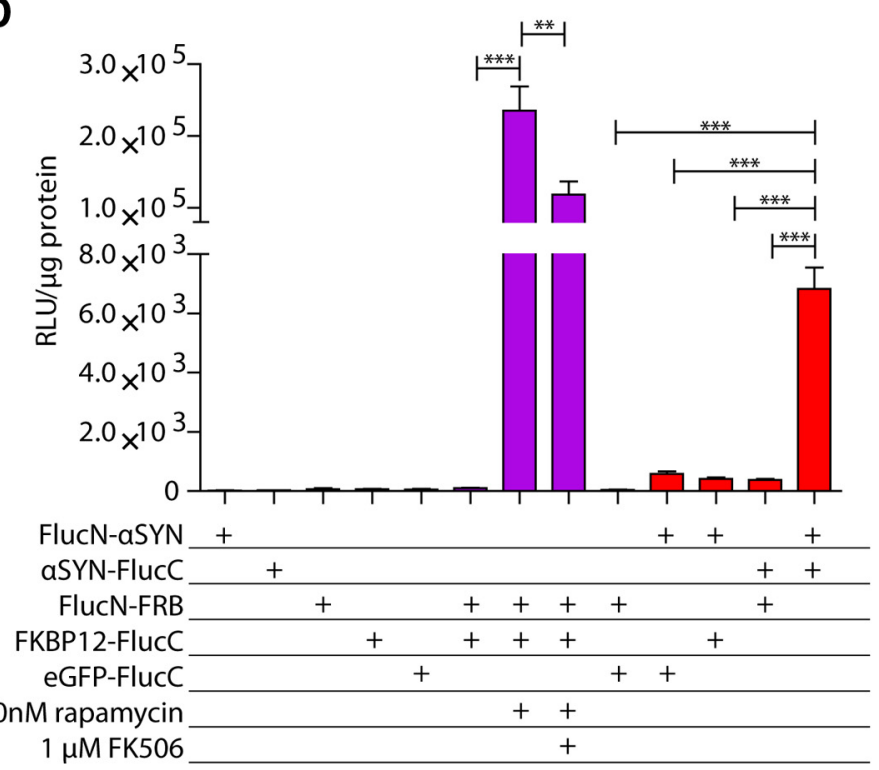

Figure 1. Split-firefly luciferase reporter assay to visualize $\alpha$ SYN oligomerization in cell culture. $A$, Principle of a bioluminescent PCA. FlucN and FlucC are fused to two interacting proteins. In case of interaction between the two proteins, the Fluc protein will be complemented, restoring its enzymatic activity. In the presence of its substrate luciferin, protein-protein interaction will lead to production of light. $\boldsymbol{B}$, Design of split-Fluc fusion constructs, drawn to scale. C, Western blot showing expression of different protein fusions, detected with a polyclonal anti-Fluc antibody in SHSY5Y cells transduced with split-Fluc LV vectors. This antibody allows detection of both FlucN and FlucC. D, Luciferase activity of SHSY5Y cells transduced with different combinations of split-Fluc LV vectors. Transduction with one split-Fluc LV vector did not result in luminescence. The functionality of the split-luciferase system was validated by the known rapamycin-induced interaction between FRB and FKBP12 (purple bars), which was inhibited by addition of FK506. Data are mean \pm SEM. Statistical analysis: one-way ANOVA combined with Bonferroni correction for multiple testing $\left(F_{(2,54)}=28.5\right) .{ }^{* * *} p<0.0001 .{ }^{* *} p<0.01$. Red bars represent cells transduced with at least one split-Fluc-aSYN LV. Cells transduced with two split-Fluc- $\alpha$ SYN LVs showed $11-160$ times higher BLI signals compared with cells transduced with different combinations of split-Fluc LV vectors, showing that interaction between two or more $\alpha$ SYN proteins results in productive luciferase complementation. Data are mean \pm SEM. Statistical analysis: one-way ANOVA combined with Bonferroni correction for multiple testing $\left(F_{(4,90)}=80.0\right) .{ }^{* * *} p<0.0001$. Data are pooled data from 3 independent experiments; $n=19$ per condition.

amount of $10 \%$ ethanol in $0.9 \%$ sterile saline containing $1 \%$ Tween 80 was used as placebo. The BLI signal from mice expressing FlucN- $\alpha \mathrm{SYN}$ $+\alpha \mathrm{SYN}$-FlucC was normalized to that of mice expressing eGFP-T2AFluc, per treatment and per time point.

Statistical analysis. All statistical analyses were performed in Prism 5.0 (GraphPad Software). For multiple group comparisons at a single time point (e.g., luciferase assays in cell culture), one-way ANOVA followed by a post hoc Bonferroni or Dunnett's test to correct for multiple testing was used. In case of non-normality, the nonparametric equivalent (Kruskal-Wallis test) was chosen, followed by Dunn's test. In case only two groups were compared, a Student's $t$ test or Mann-Whitney $U$ test (non-normality) was used. For multiple comparisons at different time points (e.g., BLI of different groups of animals over time), repeated measures mixed-model ANOVA was performed, followed by a Bonferroni post test.

\section{Results}

Visualization of $\alpha S Y N$ oligomerization in cell culture using split-Fluc LV vectors

In a bioluminescent PCA, the $\mathrm{N}$-terminal (FlucN) and C-terminal (FlucC) part of Fluc are fused to each of two interact- ing proteins (Fig. $1 A$ ). Physical interaction of the latter two proteins has the potential to reconstitute the Fluc reporter protein, recovering activity and resulting in the production of visible light upon addition of the substrate luciferin. The orientation of the Fluc components in relation to the protein of interest greatly influences the functionality of the complemented Fluc protein (Paulmurugan and Gambhir, 2007; Luker et al., 2011; Leng et al., 2013). Moreover, for the development of a fluorescent PCA, different orientations of the two halves of GFP, GFP-N and GFP-C, in relation to $\alpha \mathrm{SYN}$ were compared, showing the highest complementation efficiency when GFP-N was positioned at the $\mathrm{N}$-terminal and GFP-C at the C-terminal of $\alpha \mathrm{SYN}$ (Outeiro et al., 2008). For this reason, FlucN was positioned at the N-terminal and FlucC at the C-terminal part of the proteins of interest (Fig. $1 B)$. To monitor $\alpha \mathrm{SYN}$ oligomerization, both FlucN and FlucC were fused to $\alpha \mathrm{SYN}$. As positive controls, FlucN and FlucC fused to the FRB domain or FKBP12, respectively, were constructed. The fusion construct eGFP-FlucC was generated as a negative control. After transduction of SHSY5Y cells with single split-Fluc 
A

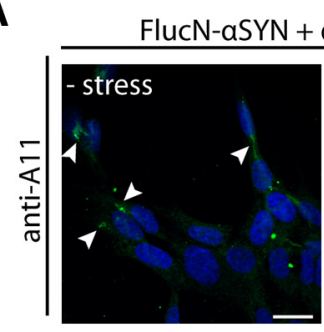

B

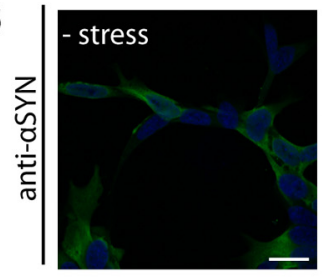

C

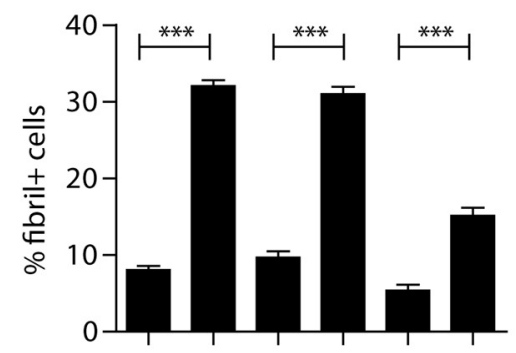

FlucN-aSYN + aSYN-FlucC ++

WT-aSYN

empty SHSY5Y

stress
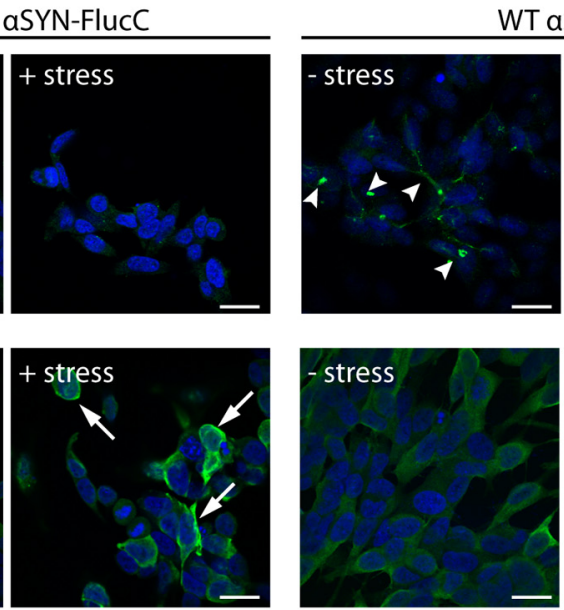

WT ASYN
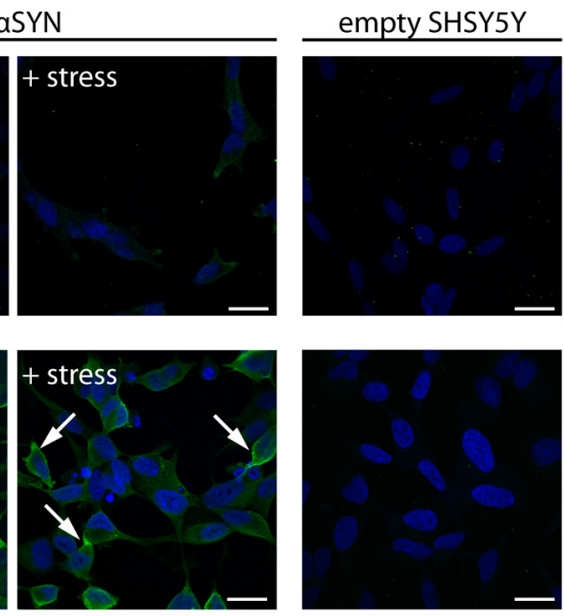

D
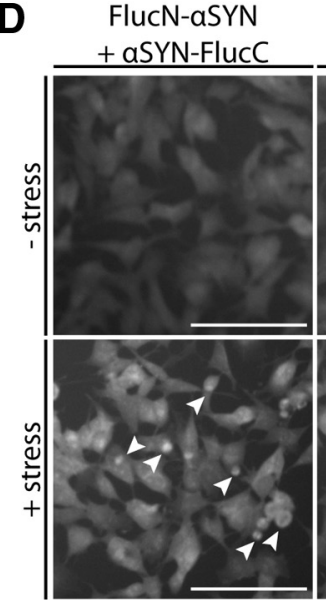

WT ASYN

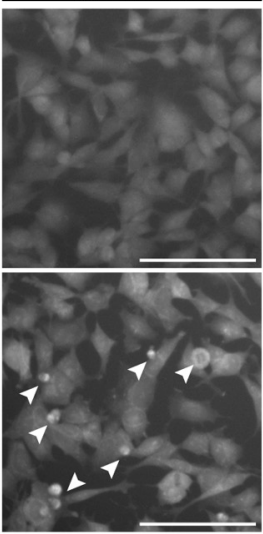

Figure 2. Immunocytochemical characterization of split Fluc-tagged $\alpha$ SYN species in cell culture. $A$, Under standard conditions, $\alpha$ SYN oligomers (arrowheads, detected with an oligomer-specific A11 antibody) are present in SHSY5Y cells expressing FlucN- $\alpha$ SYN $+\alpha$ SYN-FlucC (left). Oligomers were also present in cells expressing untagged WT $\alpha$ SYN (middle, arrowheads). Oligomers could not be detected in empty cells (right). $\boldsymbol{B}$, Immunocytochemical staining with an anti- $\alpha$ SYN antibody. Under oxidative stress conditions, accumulation of $\alpha$ SYN (arrows) is induced in cells expressing FlucN- $\alpha$ SYN $+\alpha$ SYN-FlucC (left), comparable with cells expressing untagged WT $\alpha$ SYN (middle). These accumulations were absent in standard conditions. $\boldsymbol{A}, \boldsymbol{B}, \mathrm{Scale}$ bar, $20 \mu \mathrm{m}$. $\boldsymbol{C}, \boldsymbol{D}$, High content automated quantification of $\alpha$ SYN fibril formation. C, Data are mean \pm SEM ( $n=6$ per condition). Statistical analysis: one-way ANOVA combined with Bonferroni correction for multiple testing $\left(F_{(5,30)}=198.5\right) .{ }^{* * *} p<0.001$. D, Pictures taken with IN Cell Analyzer for high-content analysis, showing detection of $\alpha$ SYN fibrils (arrowheads) via Thio-S staining. Scale bar, $100 \mu \mathrm{m}$.

LV vectors, expression of the respective protein fragments was evidenced (Fig. 1C). As expected, single split-Fluc LV vectors did not result in luciferase activity (Fig. 1D).

As a first step to validate the functionality of the splitluciferase system, we analyzed the known rapamycin induced interaction between FRB and FKBP12 (Fig. 1D, purple bars). SHSY5Y cells cotransduced with FlucN-FRB and FKBP12-FlucC $L V$ vectors showed a $>2000$-fold increase in BLI signal upon addition of $10 \mathrm{~nm}$ rapamycin $(p<0.0001)$. This interaction was inhibited twofold upon addition of $1 \mu \mathrm{M}$ FK506 $(p<0.01)$. Neither rapamycin nor FK506 inhibited luciferase activity as such (data not shown).

To monitor $\alpha \mathrm{SYN}$ oligomerization, cells were transduced with FlucN- $\alpha \mathrm{SYN}+\alpha \mathrm{SYN}$-FlucC LV vectors and compared with control cells transduced with different combinations of split-Fluc LV vectors (Fig. 1D, red bars). The BLI signal of cells transduced with both split-Fluc- $\alpha$ SYN LV vectors was $>11$-fold higher compared with cells transduced with one split-Fluc- $\alpha$ SYN LV vector in combination with a split-Fluc control LV vector $(p<0.001)$. The BLI signal of cells expressing both split-Fluc$\alpha \mathrm{SYN}$ fusion proteins was even 160 times higher compared with cells expressing FlucN-FRB + eGFP-FlucC $(p<0.001)$. These data indicate that interaction between two or more $\alpha \mathrm{SYN}$ proteins results in productive luciferase complementation.

\section{Luciferase complementation in cell culture results from $\alpha S Y N$ oligomerization}

To define the specific $\alpha \mathrm{SYN}$ species at the origin of the BLI signal, cells expressing FlucN- $\alpha \mathrm{SYN}$ and $\alpha \mathrm{SYN}$-FlucC were subjected to immunocytochemical analysis. Under standard culture conditions, we identified oligomeric $\alpha \mathrm{SYN}$ species with the oligomerspecific A11 antibody (Kayed et al., 2003), comparable with cells expressing untagged WT $\alpha$ SYN (Fig. 2A). In agreement with our previous observations (Gerard et al., 2010), $\alpha$ SYN accumulation was not detected under standard culture conditions (Fig. 2B), suggesting that the bimolecular interaction detected in the luciferase complementation assay represents preaggregate oligomeric $\alpha S Y N$ species.

Next, we evaluated whether the rather large Fluc-tags (FlucN $=44 \mathrm{kDa}$; FlucC $=17 \mathrm{kDa}$, respectively), might affect the aggregation properties of $\alpha \mathrm{SYN}$. Cells expressing FlucN- $\alpha \mathrm{SYN}+$ $\alpha \mathrm{SYN}$-FlucC were subjected to oxidative stress to induce $\alpha \mathrm{SYN}$ aggregation (Gerard et al., 2010). Cells expressing untagged WT $\alpha \mathrm{SYN}$ were analyzed in parallel. Immunocytochemical stainings 
A

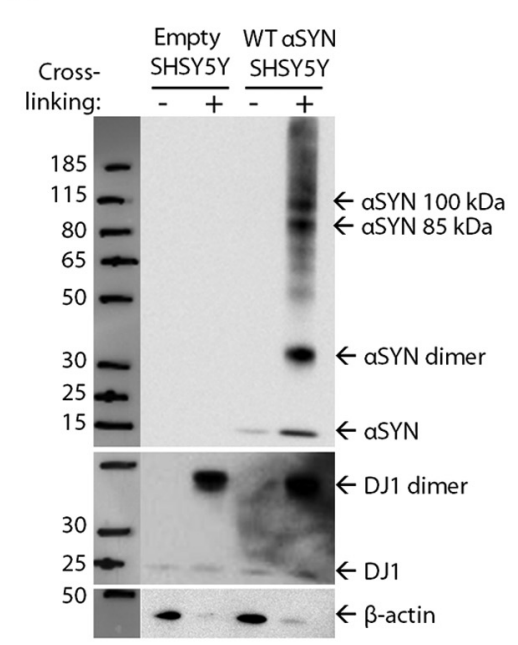

B
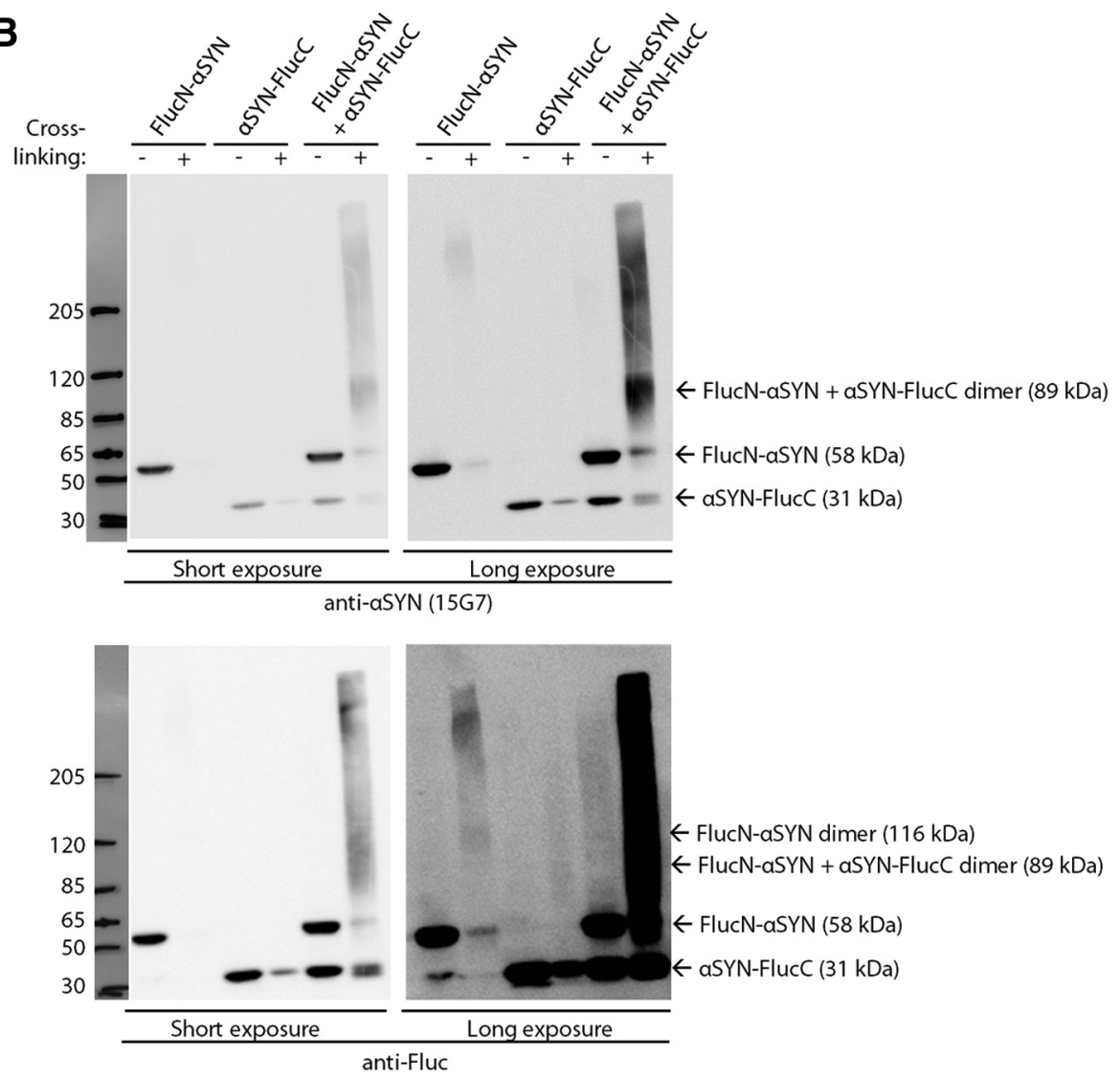

Figure 3. Cross-linking reveals $\alpha$ SYN oligomers of different sizes in cell culture. $A, B$, Cytosolic fractions from SHSY5Y cells, treated with DMSO (-) or 1 mM DSG (+), were loaded and analyzed by immunoblotting. $A$, Cytosolic fractions from empty cells or cells overexpressing WT untagged $\alpha$ SYN were analyzed. Immunodetection with the $15 \mathrm{G}$ antibody revealed $\alpha$ SYN monomers and oligomers of different sizes, with dimers and $\sim 85 \mathrm{kDa}$ and $\sim 100 \mathrm{kDa}$ oligomers as the most prominent oligomers. The $15 \mathrm{G} 7$ antibody does not detect endogenous $\alpha$ SYN. The efficiency of cross-linking was evidenced by the detection of DJ1 dimers. Detection of $\beta$-actin was impaired by the cross-linking, as previously described (Newman et al., 2013). $\boldsymbol{B}$, Immunodetection of cytosolic fractions from cells expressing FlucN- $\alpha$ SYN, $\alpha$ SYN-FlucC, or both fusion proteins with the $15 \mathrm{G} 7$ and Fluc antibodies revealed the presence of monomers and oligomers of different sizes. The size of the $\sim 90 \mathrm{kDa}$ band detected in cells expressing both fusion proteins and the fact that this band was not detected in the other two cell lines strongly suggest that this band represents a dimer formed by FlucN- $\alpha$ SYN and $\alpha$ SYN-FlucC.

revealed increased intensity of $\alpha \mathrm{SYN}$ immunoreactivity mainly near the cell borders with some clear accumulations, similar to cells expressing WT $\alpha$ SYN (Fig. 2B). High content analysis-based automated quantification, based on the detection of fibrillary $\alpha S Y N$ via Thio-S staining, showed a 3.2 -fold increase in fibril formation in cells expressing FlucN- $\alpha \mathrm{SYN}+\alpha \mathrm{SYN}$-FlucC $(p<$ 0.001 ), which was comparable with the increase in cells expressing untagged WT $\alpha \mathrm{SYN}$ (Fig. 2C,D), underscoring that the Fluctags do not significantly affect the aggregation behavior of $\alpha \mathrm{SYN}$ under oxidative stress conditions. Of note, $\alpha \mathrm{SYN}$ oligomerization could not be monitored with the bioluminescent PCA under oxidative stress conditions because Fluc activity is sensitive to reactive oxygen species (Czupryna and Tsourkas, 2011; and data not shown).

In conclusion, the bioluminescent PCA can detect $\alpha \mathrm{SYN}$ oligomerization by productive luciferase complementation in cell culture.

\section{Biochemical analysis of $\alpha S Y N$ oligomers in cell culture}

Next, we evaluated the biochemical nature of the $\alpha \mathrm{SYN}$ oligomers that were generated in SHSY5Y cells expressing FlucN$\alpha \mathrm{SYN}+\alpha \mathrm{SYN}$-FlucC. to trap native assemblies of $\alpha \mathrm{SYN}$ is through cross-linking on intact cells using small, cell-permeable cross-linkers. This approach previously allowed detection of different sizes of endogenous $\alpha \mathrm{SYN}$ oligomers in human erythro- leukemia cells (Bartels et al., 2011; Dettmer et al., 2013). First, we verified whether this cross-linking technique allowed detection of oligomers of overexpressed WT untagged $\alpha \mathrm{SYN}$ in SHSY5Y cells. We used DSG, a cell-permeable cross-linker that forms covalent nonreducible bonds between lysine residues, of which $\alpha \mathrm{SYN}$ contains 15 . Immunoblotting after cross-linking revealed different sizes of $\alpha$ SYN oligomers in SHSY5Y cells overexpressing WT $\alpha$ SYN, with dimers and oligomers of $\sim 85 \mathrm{kDa}$ and $\sim 100$ $\mathrm{kDa}$ as the most prominent oligomers (Fig. $3 A$ ). As a positive control for the cross-linking technique, we also detected endogenous DJ1 in its known physiological dimeric form (Fig. $3 A$ ).

Next, we applied the cross-linking protocol on SHSY5Y cells that either expressed FlucN- $\alpha \mathrm{SYN}$ or $\alpha \mathrm{SYN}$-FlucC or cells expressing both fusion proteins (Fig. $3 B$ ). In the cells expressing both fusion proteins, a distinct band of $\sim 90 \mathrm{kDa}$ was detected, together with other high-molecular-weight (HMW) oligomers. The size of this $\sim 90 \mathrm{kDa}$ band, and the fact that it was not detected in the other two cell lines strongly suggests that this band represents a dimer formed by FlucN- $\alpha \mathrm{SYN}$ and $\alpha \mathrm{SYN}-$ FlucC. Of note, in cells expressing FlucN- $\alpha S Y N$, cross-linking also revealed the presence of a dimer (of $\sim 116 \mathrm{kDa}$ ) and other HMW oligomers, although to a weaker extent. In cells expressing $\alpha \mathrm{SYN}$ FlucC, the different oligomers were more difficult to distinguish. In conclusion, oligomers of different sizes, ranging from dimers to HMW oligomers, are generated in cells expressing FlucN- 
$\alpha S Y N+\alpha S Y N-F l u c C$, which correspond to the successful luciferase complementation signal.

\section{Noninvasive imaging of $\alpha \mathrm{SYN}$ oligomerization in mouse striatum up to 8 months after injection using split-Fluc AAV vectors}

Next, we set out to monitor $\alpha \mathrm{SYN}$ oligomerization noninvasively in the mouse brain using our bioluminescent PCA. After validating the system in cell culture, we produced split-Fluc AAV vectors. We opted for AAV2/7 vectors instead of LV vectors for the in vivo experiments because of their higher transduction efficiency of dopaminergic neurons in the brain (Van der Perren et al., 2011). Equal titers of two AAV vectors (a total of $1.8 \times 10^{8} \mathrm{GC}$ per animal) were stereotactically injected in the striatum of albino mice ( $n=4$ per group). One group was injected with FlucN$\alpha \mathrm{SYN}+\alpha \mathrm{SYN}$-FlucC AAV vectors and a control group with FlucN-FRB $+\alpha$ SYN-FlucC AAV vectors to control for aspecific luciferase signal. The animals were regularly scanned over time, until 8 months after injection. The group injected with the two split-Fluc- $\alpha$ SYN AAV vectors showed 5.9-fold higher BLI signals at all time points compared with the control group (Fig. $4 A, B$; $p=0.0002)$. These data were confirmed in an independent experiment with new vector productions (data not shown). This demonstrates that, in line with the cell culture experiments, $\alpha \mathrm{SYN}$ oligomerization results in productive luciferase complementation in vivo.

Long-term noninvasive monitoring of $\alpha \mathrm{SYN}$ oligomerization in the same groups of animals allowed us to identify particular BLI kinetics. Remarkably, in the mice injected with the two splitFluc- $\alpha$ SYN AAV vectors, the BLI signal steadily increased until 5 weeks after injection In two mice, the BLI signal peaked at 3 weeks after injection and in two mice at 5 weeks after injection, which was followed by a gradual decrease in BLI signal until 9 weeks after injection, after which the signal remained stable until 8 months after injection (Fig. 4B). These kinetics were not observed in the control group, indicating that the specific BLI kinetics in the mice injected with the two split-Fluc- $\alpha$ SYN AAV vectors can be attributed to the $\alpha \mathrm{SYN}$ oligomerization process.

The mice were perfused at 8 months after injection for detailed histological analysis (Fig. 4C-H). $\alpha \mathrm{SYN}$ overexpression was detected in the striatum of both groups (Fig. 4C). Double immunofluorescent stainings revealed that $\alpha \mathrm{SYN}$ was predominantly expressed in the dopaminoceptive medium spiny neurons of the striatum (Fig. 4D). To assure that the tagged $\alpha \mathrm{SYN}$ species are still susceptible to pathological modifications, we performed additional stainings for typical phenotypic markers. In both groups, transduced cells contained aggregated, phosphorylated S129p and ubiquitinated $\alpha S Y N$ (Fig. $4 E-G$ ), features that are associated with $\alpha$ SYN pathology. In addition, fibrillar $\alpha$ SYN species were detected by Thio-S staining (Fig. 4H). Compared with the noninjected side, there were no apparent signs of cell death in the injected striatum (Fig. 4D).

Together, these data indicate that, following injection of splitFluc AAV vectors in the striatum, $\alpha \mathrm{SYN}$ oligomerization can be monitored noninvasively by BLI. Moreover, the tagged $\alpha S Y N$ species still generate pathologically relevant $\alpha \mathrm{SYN}$ species.

\section{Biochemical analysis of $\alpha \mathrm{SYN}$ oligomers in mouse striatum}

Next, we aimed to analyze the presence and size of the $\alpha \mathrm{SYN}$ oligomers generated in vivo. To our knowledge, cross-linking of endogenous or overexpressed $\alpha \mathrm{SYN}$ in mouse brain has not been demonstrated before. Therefore, we first performed cross-linking on transgenic Thy1-A30P $\alpha S Y N$ mice (Kahle et al., 2000), WT mice injected with an AAV encoding WT untagged $\alpha \mathrm{SYN}$, and WT mice as negative control. In transgenic Thyl-A30P $\alpha \mathrm{SYN}$ mice and in mice injected with an AAV- $\alpha S Y N$, cross-linking revealed different sizes of $\alpha$ SYN oligomers, with mainly dimers and $\sim 65 \mathrm{kDa}$ and $\sim 85 \mathrm{kDa}$ oligomers (Fig. $5 A$ ). Interestingly, in mice injected with AAV- $\alpha \mathrm{SYN}, \alpha \mathrm{SYN}$ dimers could even be detected without cross-linking (Fig. 5A). In line with the cell culture experiments, the effectiveness of cross-linking was demonstrated by the detection of DJ1 dimers (Fig. 5A). Next, we applied the crosslinking protocol to detect $\alpha \mathrm{SYN}$ oligomers in brain homogenates of mice $4 \mathrm{~d}, 4$ weeks, or 17 weeks after injection with FlucN- $\alpha \mathrm{SYN}$ $+\alpha \mathrm{SYN}$-FlucC AAV vectors. The expression of the fusion proteins markedly increased between $4 \mathrm{~d}$ and 4 weeks after injection (Fig. 5B). From 4 weeks onwards, monomers and oligomers could be detected in cross-linked brain extracts with antibodies against $\alpha S Y N$ and Fluc (Fig. $5 B$ ). In line with the cell culture experiments, an oligomeric band of $\sim 90 \mathrm{kDa}$, suggesting that a dimer between the two fusion proteins could be distinguished. These findings suggest that, in mouse brain, $\alpha \mathrm{SYN}$ oligomers ranging from dimers to HMW oligomers are formed, which are presumably responsible for the successful luciferase complementation.

\section{BLI of $\alpha$ SYN oligomerization and dopaminergic cell death in mouse SN}

In a next step, we monitored $\alpha \mathrm{SYN}$ oligomerization in the $\mathrm{SN}$, the main region affected in $\mathrm{PD}$ patients. As in the striatum, a mixture of two split-Fluc AAV vectors (a total of $7.0 \times 10^{8} \mathrm{GC}$ per animal) was stereotactically injected in the $\mathrm{SN}$ of albino mice. One group was injected with FlucN- $\alpha \mathrm{SYN}+\alpha \mathrm{SYN}$-FlucC AAV vectors and a control group was injected with FlucN-FRB $+\alpha$ SYN-FlucC AAV vectors ( $n=5$ per group). The animals were scanned regularly until 6 months after injection (Fig. $6 A, B$ ). In line with striatal injections, the BLI signal of the group injected with FlucN- $\alpha \mathrm{SYN}+\alpha \mathrm{SYN}$ FlucC AAV vectors was 5.8-fold higher over all time points than the control group (Fig. $6 A, B ; p=0.002$ ). In both groups, the BLI signal increased until 1 or 3 weeks after injection, followed by a decrease until 6 weeks after injection after which the signal remained stable up to 6 months after injection These data were confirmed in an independent experiment in which the animals were scanned until 2 months after injection (data not shown).

Again in both groups, histological analysis revealed $\alpha \mathrm{SYN}$ pathology by the presence of aggregated $\alpha \mathrm{SYN}$ and $\alpha \mathrm{SYN}$ phosphorylated at S129 (Fig. 6C,D). Immunohistological detection of $\mathrm{TH}$ revealed a distinct dopaminergic cell death in the $\mathrm{SN}$ of both groups (Fig. 6E). Immunostaining for the dopamine active transporter and the pan-neuronal marker $\mathrm{NeuN}$ confirmed loss of dopaminergic neurons in the SN (data not shown and Fig. 6G). Compared with the noninjected side, stereological quantification revealed $88 \pm 6 \%$ dopaminergic cell loss in mice expressing FlucN- $\alpha \mathrm{SYN}+\alpha \mathrm{SYN}-$ FlucC and $73 \pm 9 \%$ dopaminergic cell loss in mice expressing FlucN-FRB $+\alpha S Y N-F l u c C$, respectively (Fig. $6 F$ ). In mice perfused at 2 months after injection, a similar degree of dopaminergic degeneration was detected (data not shown). Triple immunofluorescent stainings at 6 months after injection revealed that $\alpha \mathrm{SYN}$ is mainly confined to the surviving dopaminergic neurons and the surrounding nondopaminergic neurons (Fig. 6G). The dopaminergic cell loss was further corroborated by loss of dopaminergic fibers in the striatum (Fig. $6 \mathrm{H}$ ). Stereological quantification of the striatal $\mathrm{TH}$ positive volume revealed a $75 \pm 14 \%$ reduction in mice expressing FlucN- $\alpha$ SYN $+\alpha$ SYN-FlucC and $73 \pm 22 \%$ reduction in mice expressing FlucN-FRB $+\alpha \mathrm{SYN}-$ FlucC, re- 


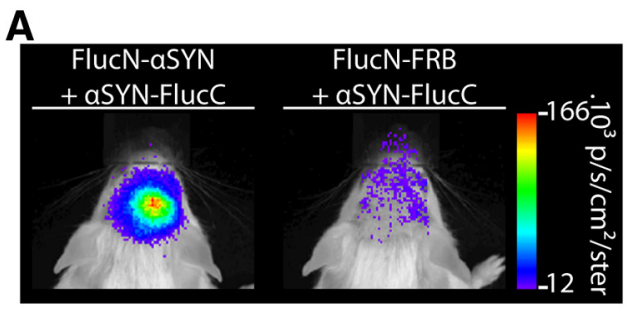

C
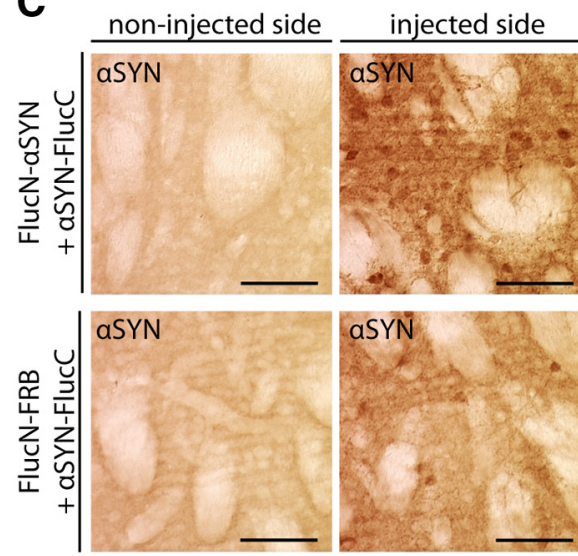

E

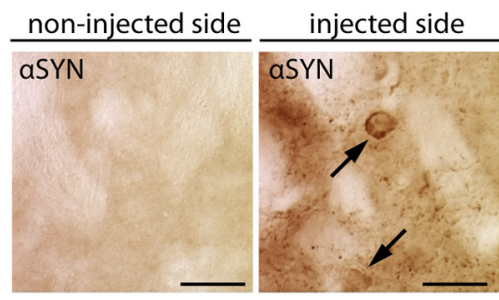

$\mathbf{F}$

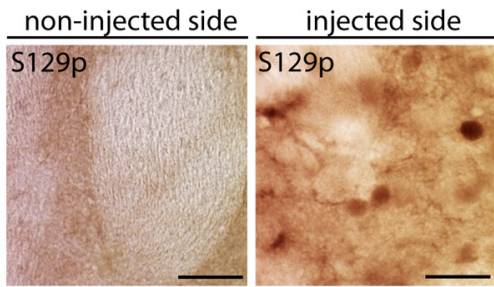

B

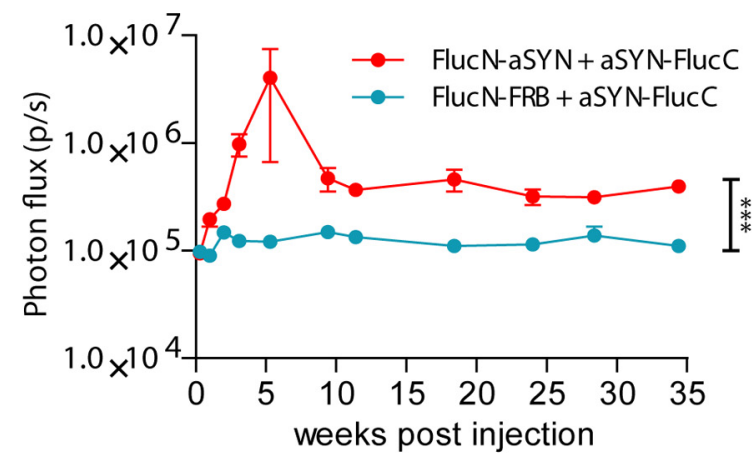

non-injected side
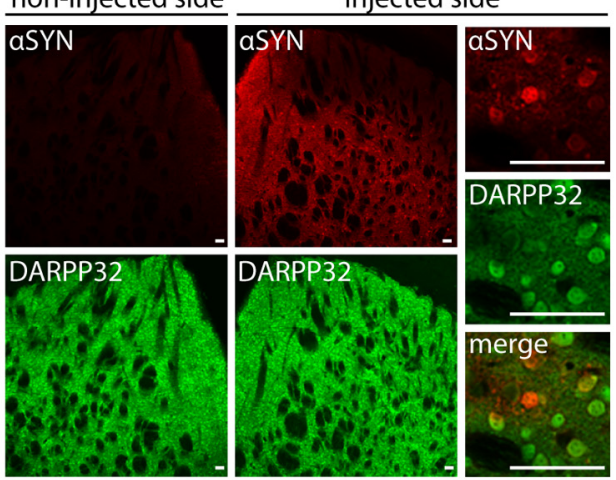

G
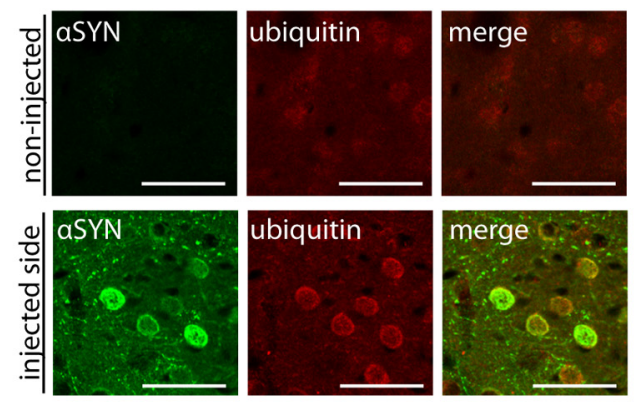

H
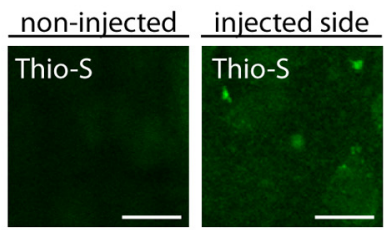

Figure 4. Noninvasive BLI of $\alpha$ SYN oligomerization in mouse striatum. $A, B$, Different combinations of different split-Fluc AAV vectors as indicated were injected in the right striatum of albino mice ( $n=4$ per group). Animals were scanned until 8 months after injection $A$, Representative BLI images at 3 weeks after injection are shown, revealing a BLI signal originating from the site of injection. $\boldsymbol{B}$, Mice expressing FlucN- $\alpha$ SYN $+\alpha$ SYN-FlucC showed a sixfold higher BLI signal and different kinetics compared with the control group. Data are mean \pm SEM. Statistical analysis: two-way repeated-measures ANOVA $\left(F_{(1,50)}=90.4\right) .{ }^{* * *} p=0.0002$. C, Immunohistochemical stainings showing $\alpha$ SYN expression in the striatum of both groups. Scale bar, $100 \mu \mathrm{m}$. D, Double immunofluorescent stainings show that $\alpha$ SYN (red) is mainly expressed in medium spiny neurons, detected by a DARPP32 antibody (green). Scale bar, $100 \mu \mathrm{m} . \boldsymbol{E}, \boldsymbol{F}$, Immunohistochemical stainings showed that, in both groups, transduced cells contained aggregated $\alpha$ SYN (arrows, detected with an antibody against $\alpha$ SYN) (E) and phosphorylated S129p $\alpha$ SYN (detected with an antibody against S129p $\alpha$ SYN) $(\boldsymbol{F}) . \boldsymbol{E}, \boldsymbol{F}$, Scale bar, $25 \mu \mathrm{m}$. G, Double immunofluorescent stainings show colocalization of $\alpha$ SYN (green) and ubiquitin (red) in the striatum. $\boldsymbol{H}$, Thio-S staining shows the presence of fibrillar $\alpha$ SYN in the injected striatum. $\boldsymbol{G}, \boldsymbol{H}, \mathbf{S}$ cale bar, $50 \mu \mathrm{m}$.

spective to the contralateral side (Fig. $6 \mathrm{~F}$ ). The degree of dopaminergic neurodegeneration is comparable with our previous observations with AAV-mediated overexpression of untagged WT $\alpha \mathrm{SYN}$ in the mouse SN (Oliveras-Salvá et al., 2013). Together, these data show that the tagged aSYN species retain their pathological properties in vivo.

\section{FK506 inhibits $\alpha$ SYN oligomer formation}

In a next step, we evaluated the effect of two small-molecule inhibitors on $\alpha \mathrm{SYN}$ oligomerization, first in cell culture and subsequently in mouse brain using the bioluminescent PCA. Previously, we revealed a direct link between FKBPs and $\alpha$ SYN aggregation (Gerard et al., 2006, 2010; Meuvis et al., 2010; Del- 

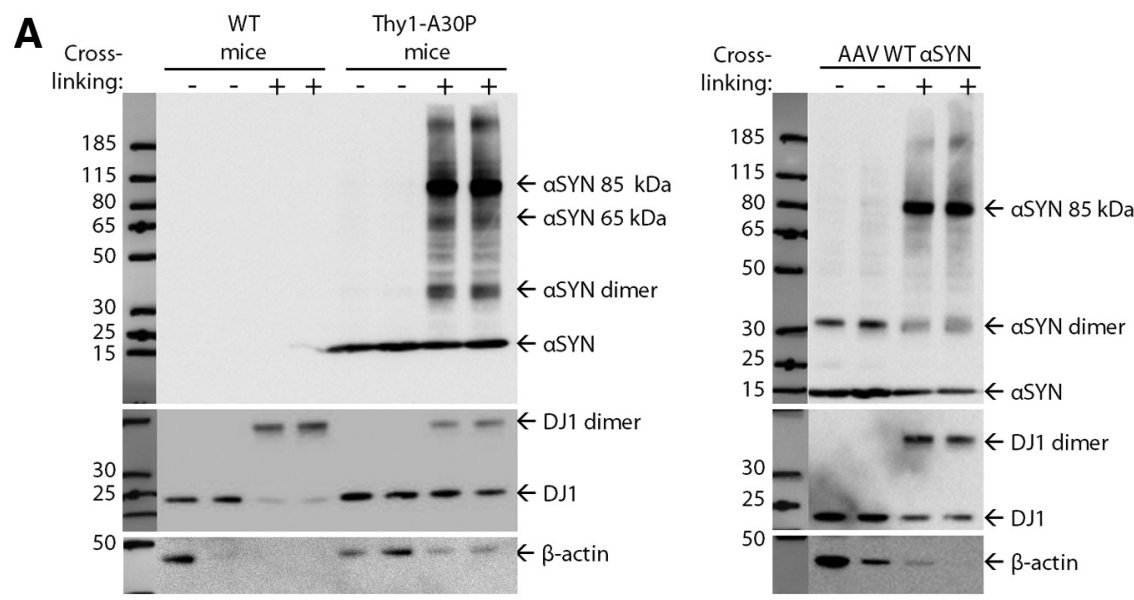

B
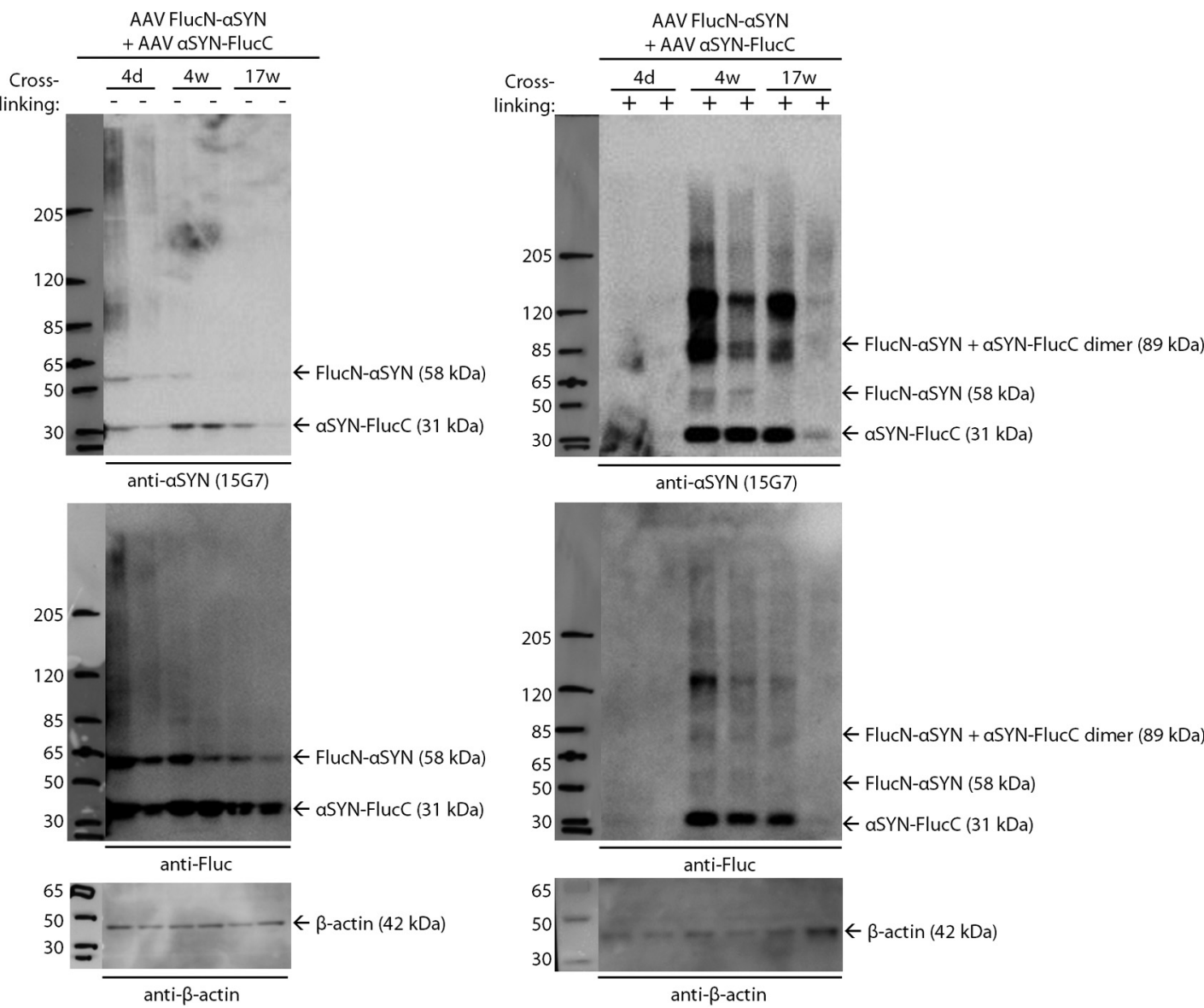

Figure 5. Cross-linking reveals $\alpha$ SYN oligomers of different sizes in mouse brain. Cytosolic fractions from mouse brain homogenates that were treated with DMSO (-) or $1 \mathrm{~mm}$ DSG $(+)$ were analyzed. The two lanes per condition represent two different animals. $A$, Analysis of cytosolic fractions from WT mice, Thy1-A3OPaSYN mice, or mice injected with AAV-WT- $\alpha$ SYN. Immunodetection with the $15 \mathrm{G} 7$ antibody of WT untagged $\alpha$ SYN in mouse brain revealed $\alpha$ SYN monomers and oligomers of different sizes, with mainly dimers and $\sim 65 \mathrm{kDa}$ and $\sim 85 \mathrm{kDa}$ oligomers. The efficiency of cross-linking was evidenced by the detection of DJ1 dimers. Detection of $\beta$-actin was impaired by the cross-linking, as previously described (Newman et al., 2013). The 15G7 antibody does not detect endogenous mouse $\alpha$ SYN. $\boldsymbol{B}$, Analysis of cytosolic brain homogenates from mice at $4 \mathrm{~d}$, 4 weeks, or 17 weeks after injection of FlucN- $\alpha$ SYN $+\alpha$ SYN-FlucC AAV vectors. Immunodetection with the $15 \mathrm{G} 7$ and Fluc antibodies revealed $\alpha$ SYN monomers and oligomers in the cross-linked samples, ranging from dimers to HMW oligomers, from 4 weeks after injection onwards.

eersnijder et al., 2011). FKBP12 was shown to increase $\alpha$ SYN fibril formation and FK506, by inhibiting FKBP12, to reduce the number of $\alpha$ SYN fibrils and to protect against cell death in a cell culture model for synucleinopathy (Gerard et al., 2010). In addition, chronic FK506 administration reduced $\alpha$ SYN aggregation and neurodegeneration in mice overexpressing $\alpha \mathrm{SYN}$ in the striatum (Gerard et al., 2010). Whether FK506 also inhibits $\alpha$ SYN oligomerization has remained unexplored.

EGCG, the main polyphenolic constituent of green tea, has generated substantial interest as potential modulator of a variety of neurodegenerative diseases (Mandel et al., 2011). In vitro, EGCG inhibits $\alpha$ SYN fibrillogenesis by direct binding to natively 
A

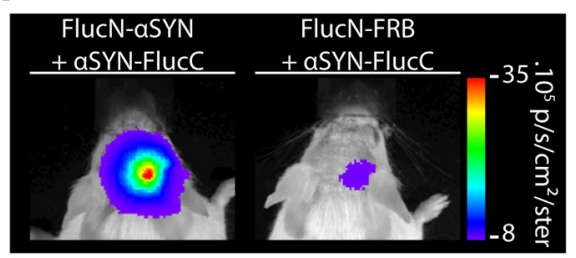

C

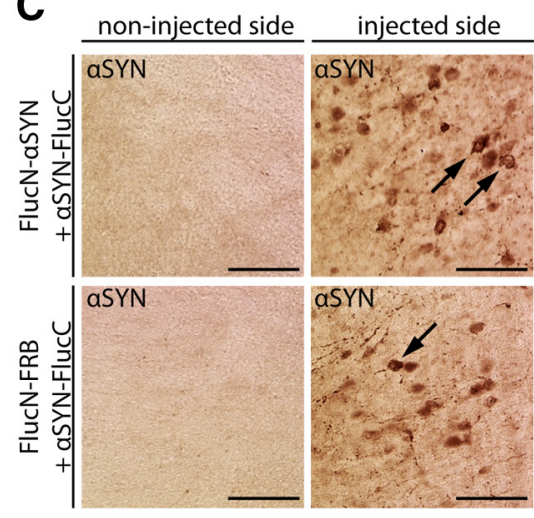

E
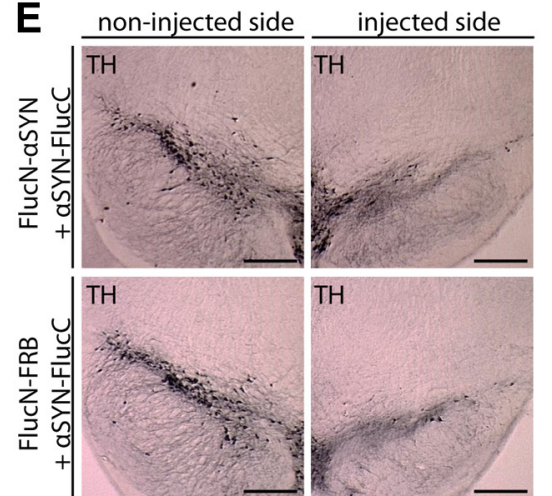

G
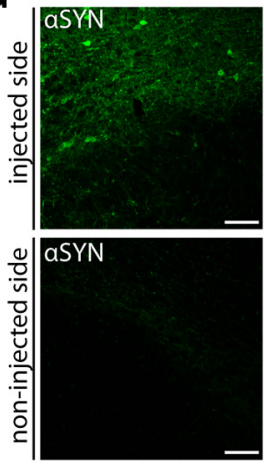

$\mathrm{TH}$
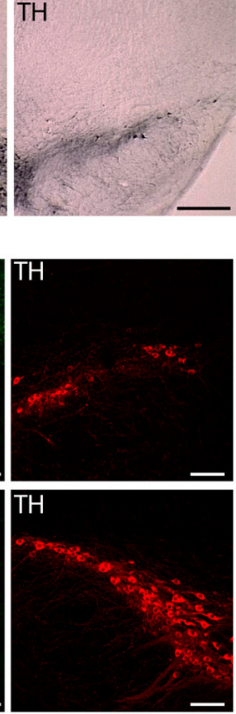

B

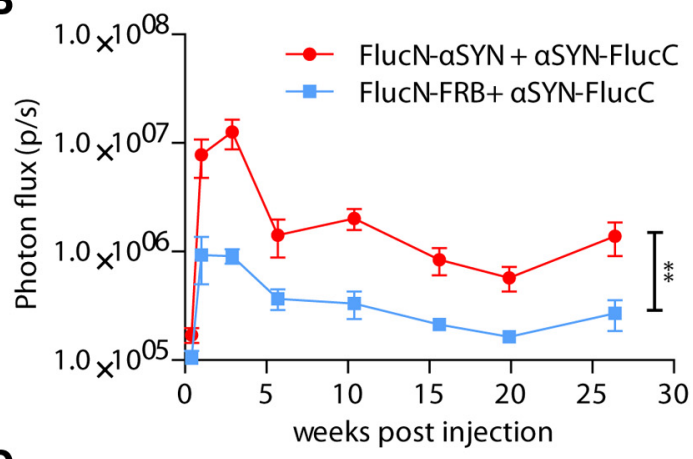

D

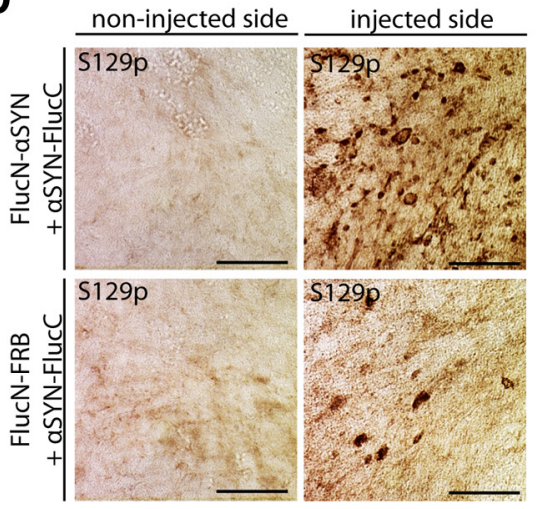

$\mathbf{F}$

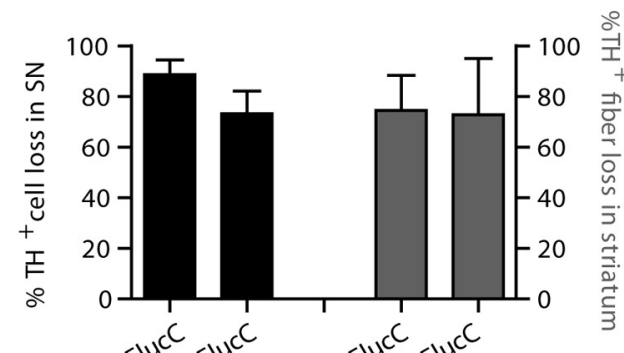

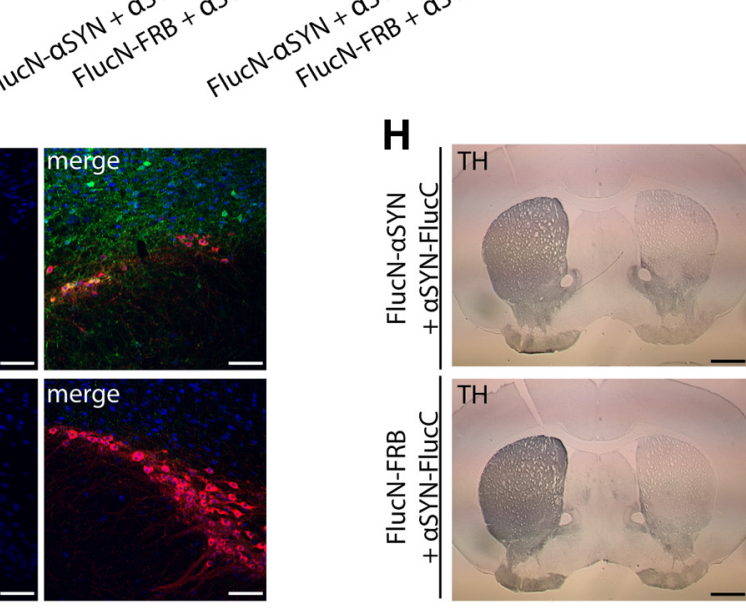

Figure 6. Noninvasive BLI of $\alpha$ SYN oligomerization and dopaminergic neurodegeneration in mouse SN. $A, B$, Different combinations of split-Fluc AAV vectors as indicated were injected in the right SN of albino mice ( $n=5$ per group). Animals were scanned until 6 months after injection $A$, Representative BLl images at 3 weeks after injection are shown, revealing a BLI signal originating from the site of injection. $B$, Mice expressing FlucN- $\alpha$ SYN $+\alpha$ SYN-FlucC showed a sixfold higher BLI signal compared with the control group. Data are mean \pm SEM. Statistical analysis: two-way repeated-measures ANOVA $\left(F_{(1,56)}=\right.$ 19.80). ${ }^{* *} p=0.002$. C, $\boldsymbol{D}$, Immunohistochemical stainings showed that, in both groups, cells in the SN contained aggregated $\alpha$ SYN (arrows, detected with an antibody against $\alpha$ SYN) and phosphorylated $S 129 p$ $\alpha$ SYN (detected with an antibody against S129p $\alpha$ SYN). C, D, Scale bar, $25 \mu \mathrm{m}$. E, Immunohistochemical detection of TH reveals a distinct dopaminergic degeneration in the injected SN in both groups. Scale bar, $250 \mu \mathrm{m} . \boldsymbol{F}$,Stereologicalquantification revealed $88 \pm 6 \%$ dopaminergiccell lossinmiceexpressing FlucN- $\alpha$ SYN $+\alpha S Y N-F l u c C(n=5)$ and $73 \pm 9 \%$ dopaminergiccell lossinmiceexpressing FlucN-FRB $+\alpha S Y N-F l u c C$ $(n=5)$, respective to the contralateral side. Therewasno statistical difference in the degree of cell loss between both groups (Student'sttest, $T_{(8)}=1.4 ; p=0.19$ ). Stereological quantification of thestriatal TH-positive volume revealed a $75 \pm 14 \%$ reduction in mice expressing FlucN- $\alpha$ SYN $+\alpha$ SYN-FlucC $(n=4)$ and $73 \pm 22 \%$ reduction in mice expressing FlucN-FRB $+\alpha S Y N-F l u c C(n=3)$, respective to the contralateral side. There was no statistical differencein the degree ofdopaminergicfiberloss between both groups (Student'sttest, $T_{(5)}=0.07 ; p=0.94$ ). G, Tripleimmunofluorescentstaining for $\alpha S Y N$, TH, andNeuN, showing that $\alpha S Y N i s m a i n l y e x p r e s s e d$ in the surviving dopaminergic neurons and surrounding nondopaminergic neurons. Scale bar, $100 \mu \mathrm{m} . \mathrm{H}, \mathrm{Immunohistochemical} \mathrm{detection} \mathrm{of} \mathrm{TH} \mathrm{in} \mathrm{the} \mathrm{striatum.} \mathrm{Scale} \mathrm{bar,} 1 \mathrm{~mm}$. 
A

C

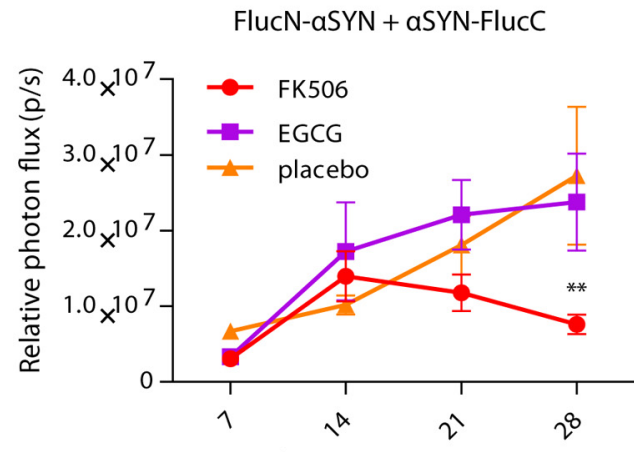

B

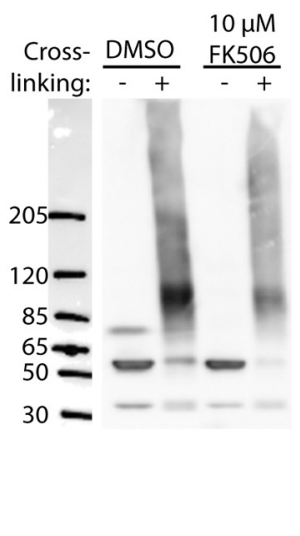

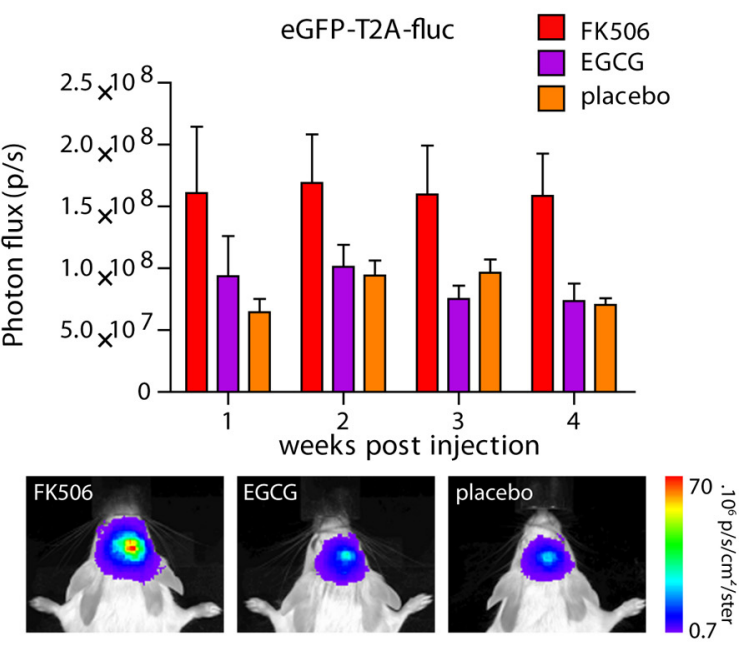

days post injection
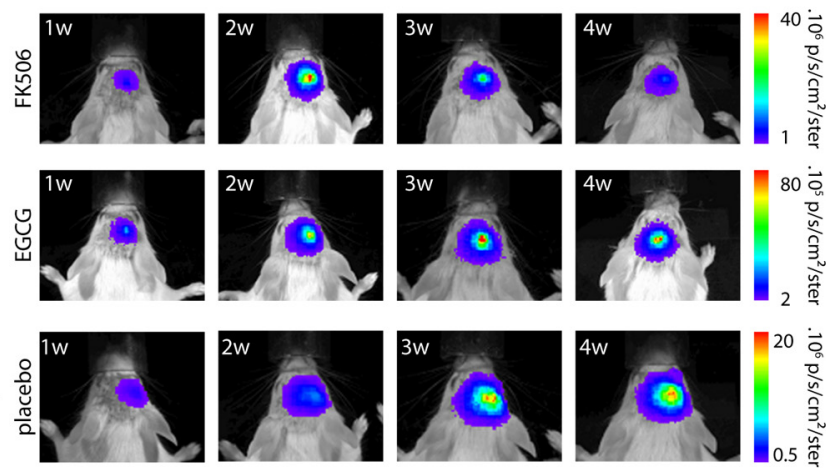

Figure 7. Effects of FK506 and EGCG on $\alpha$ SYN oligomer formation in cell culture and in mouse brain. A, Left, FK506 or EGCG was added to SHSY5Y cells stably overexpressing FlucN- $\alpha$ SYN + $\alpha$ SYN-FlucC or overexpressing eGFP-T2A-Fluc, to verify the effect on luciferase activity of full-length Fluc. The luciferase activity from cells expressing FlucN- $\alpha$ SYN $+\alpha S Y N-F l u c C$ was normalized to DMSO and to the luciferase activity of cells expressing eGFP-T2A-Fluc. Addition of $10 \mu \mathrm{m}$ FK506 resulted in a 33\% inhibition of $\alpha$ SYN oligomerization compared with DMSO. Data are mean \pm SEM from four independent experiments ( $n=24$ per condition). Statistical analysis: one-way ANOVA combined with Bonferroni correction for multiple testing $\left(F_{(2,69)}=7.64\right)$. ${ }^{* * *} p<0.001$. Right, Biochemical analysis of cells overexpressing FlucN- $\alpha$ SYN $+\alpha$ SYN-FlucC treated with $10 \mu \mathrm{M} \mathrm{FK506} \mathrm{or} \mathrm{DMSO.} \mathrm{FK506} \mathrm{treatment} \mathrm{resulted} \mathrm{in} \mathrm{a} \mathrm{23 \%} \mathrm{reduction} \mathrm{in} \mathrm{the} \mathrm{oligomer/monomer} \mathrm{ratio} \mathrm{(} p=$ $0.09 ; n=3)$. Immunodetection was performed with the $15 \mathrm{G}$ antibody. $\boldsymbol{B}$, Albino mice were stereotactically injected with eGFP-T2A-Fluc AAV in the striatum and received chronic treatment of 5 $\mathrm{mg} / \mathrm{kg} / \mathrm{d} \mathrm{FK506}(n=8), 20 \mathrm{mg} / \mathrm{kg} / \mathrm{d} \mathrm{EGCG}(n=4)$, or placebo $(n=8)$. FK506 treatment resulted in a twofold higher BLI signal compared with the placebo group at all time points. Data are mean \pm SEM from two independent experiments. Statistical analysis: two-way repeated-measures ANOVA combined with Bonferroni correction for multiple testing $\left(F_{(1,42)}=4.49, p=0.052\right)$. Bottom, Representative bioluminescent images. C, Albino mice were stereotactically injected with FlucN- $\alpha \mathrm{SYN}+\alpha \mathrm{SYN}$-FlucC AAVs in the striatum and received chronic treatment of $5 \mathrm{mg} / \mathrm{kg} / \mathrm{d}$ FK506 $(n=$ $13), 20 \mathrm{mg} / \mathrm{kg} / \mathrm{d}$ EGCG $(n=8)$, or placebo $(n=16)$. The BLI signal from mice expressing FlucN- $\alpha S Y N+\alpha S Y N-F l u c C$ was normalized to that of mice expressing eGFP-T2A-Fluc, per treatment and per time point. FK506 treatment inhibited $\alpha$ SYN oligomerization starting from 3 weeks after injection, resulting in a 3.6-fold inhibition compared with the placebo group at 4 weeks after injection Data are mean \pm SEM from two independent experiments. Statistical analysis: two-way repeated-measures ANOVA combined with Bonferroni correction for multiple testing $\left(F_{(2,102)}=1.97\right)$. ${ }^{* *} p<0.01$. Right, Representative bioluminescent images.

unfolded $\alpha \mathrm{SYN}$, thereby preventing its conversion into toxic, on-pathway aggregation intermediates, through promotion of nontoxic, off-pathway, seeding-incompetent $\alpha \mathrm{SYN}$ oligomers (Ehrnhoefer et al., 2008; Caruana et al., 2011). Moreover, EGCG also remodels preexisting $\alpha \mathrm{SYN}$ oligomers and fibrils into smaller, benign aggregates (Bieschke et al., 2010; Caruana et al., 2011). However, the effect of EGCG on $\alpha \mathrm{SYN}$ oligomerization and fibrillization in vivo remained uninvestigated thus far.

To evaluate the effect of FK506 and EGCG on $\alpha$ SYN oligomerization in cell culture, SHSY5Y cells expressing FlucN$\alpha \mathrm{SYN}+\alpha \mathrm{SYN}$-FlucC were exposed to either $10 \mu \mathrm{M}$ FK506 or 25 $\mu \mathrm{M}$ EGCG. To verify whether FK506 and EGCG influence the enzymatic activity of full-length Fluc, $10 \mu \mathrm{M}$ FK506 or $25 \mu \mathrm{M}$ EGCG were also added to cells expressing eGFP-T2A-Fluc. No significant effects of the compounds on FLuc activity were observed (data not shown). In cells expressing FlucN- $\alpha \mathrm{SYN}+$ $\alpha \mathrm{SYN}-$ FlucC, addition of $10 \mu \mathrm{M}$ FK506 resulted in a 33\% reduction in $\alpha \mathrm{SYN}$ oligomerization compared with DMSO (Fig. 7A; $p<0.001$ ), whereas EGCG did not affect $\alpha$ SYN oligomerization (Fig. 7A). Biochemical analysis of cells expressing FlucN- $\alpha \mathrm{SYN}+$ $\alpha \mathrm{SYN}-$ FlucC treated with FK506 showed a reduction in the amount of $\alpha \mathrm{SYN}$ oligomers after cross-linking compared with cells treated with DMSO (Fig. 7A).

Next, we evaluated the effect of chronic administration of FK506 and EGCG on $\alpha$ SYN oligomerization in the mouse striatum. A mixture of FlucN- $\alpha \mathrm{SYN}+\alpha \mathrm{SYN}$-FlucC AAV vectors (a total of $7.6 \times 10^{8} \mathrm{GC}$ per animal) was stereotactically injected in the striatum of albino mice ( $n=8-16$ per treatment group). To verify whether FK506 and EGCG influence the enzymatic activity of full-length Fluc in vivo, control animals were stereotactically injected with eGFP-T2A-Fluc AAV ( $n=4-8$ per treatment group). Remarkably, in the latter group, FK506 treatment resulted in a twofold higher BLI signal compared with placebo treatment at all time points investigated (Fig. $7 B ; p=0.05$ ). Because this might eventually confound the interpretation when evaluating the effect of FK506 on $\alpha$ SYN oligomerization, the BLI 
signal from mice expressing FlucN- $\alpha \mathrm{SYN}+\alpha \mathrm{SYN}-$ FlucC was normalized to that of mice expressing eGFP-T2A-Fluc, per treatment and per time point. In mice expressing FlucN- $\alpha \mathrm{SYN}+$ $\alpha S Y N-F l u c C$ that received placebo treatment, the BLI signal gradually increased reaching a fourfold difference between 1 and 4 weeks after injection, which is in line with the previous results (Figs. $7 C$ and $4 B$ ). Compared with the placebo group, mice treated with FK506 showed a decrease in BLI signal from 3 weeks onwards, resulting in a 3.6-fold inhibition after 4 weeks of treatment (Fig. $7 C ; p<0.01$ ). In line with the cell culture experiments, EGCG did not affect the BLI signal (Fig. 7C). FK506 thus inhibits $\alpha \mathrm{SYN}$ oligomerization both in cell culture and in mouse brain.

\section{Discussion}

Increasing evidence identifies $\alpha \mathrm{SYN}$ oligomers as the toxic species in the pathogenesis of PD and other synucleinopathies. Consequently, the development of new methods to monitor $\alpha \mathrm{SYN}$ oligomers in cell culture and in living animals is crucial. We designed a bioluminescent split-Fluc complementation assay, allowing us to detect $\alpha \mathrm{SYN}$ oligomers in cultured cells and to image $\alpha \mathrm{SYN}$ oligomerization noninvasively in mouse brain.

$\alpha S Y N$ oligomers can be identified using conformationspecific antibodies (Kayed et al., 2003; Lindersson et al., 2004; Fagerqvist et al., 2013). Alternatively, a fluorescent PCA based on split-GFP reporters was implemented for visualization of $\alpha$ SYN oligomers in cultured cells (Outeiro et al., 2008). Using a splitVenus PCA, $\alpha \mathrm{SYN}$ oligomers were detected in the cortex via 2-photon microscopy (Dimant et al., 2013). However, the slow and irreversible chromophore formation does not allow realtime monitoring of protein-protein interactions. Additionally, 2-photon microscopy does not support imaging in deep brain structures. Because complementation of luciferases is reversible, bioluminescent PCAs have a high temporal resolution, allowing near-real-time association studies. Moreover, these assays have an excellent signal-to-noise ratio and sensitivity. A bioluminescent PCA based on split-Gluc was developed to study modulators of $\alpha$ SYN oligomerization (Putcha et al., 2010). However, the spectral properties of Gluc and inability of the substrate coelenterazine to cross an intact $\mathrm{BBB}$ preclude using this system for neuroimaging in live animals. For all these reasons, we designed a bioluminescent PCA based on split-Fluc.

Split-Fluc LV vectors were optimized to monitor $\alpha$ SYN oligomers in cell culture. The combination of both split- $\alpha$ SYN LV vectors resulted in a BLI signal >11-fold higher than control cells. Next, split-Fluc AAV vectors were used to noninvasively image $\alpha \mathrm{SYN}$ oligomerization in mouse brain. Both in the striatum and in the SN, the combination of both split- $\alpha$ SYN AAV vectors resulted in a BLI signal sixfold higher than in controls, indicating that interaction between two or more $\alpha \mathrm{SYN}$ proteins results in efficient luciferase complementation.

An important aspect to consider is whether the visualized $\alpha \mathrm{SYN}$ oligomers are pathologically relevant species. In cell culture, induction of aggregation under oxidative stress conditions was comparable with untagged WT $\alpha \mathrm{SYN}$, demonstrating that the aggregation properties of $\alpha \mathrm{SYN}$ are not altered by the Fluc tags. In mouse brain, Fluc-tagged $\alpha \mathrm{SYN}$ species were ubiquitinated, a hallmark of LB pathology (Kuzuhara et al., 1988; Tofaris et al., 2003). Moreover, aggregated and phosphorylated S129p $\alpha \mathrm{SYN}$ species, the most dominant pathological modification of $\alpha \mathrm{SYN}$ in LBs (Anderson et al., 2006), were detected. Furthermore, injection of the split-Fluc $\alpha \mathrm{SYN}$ vectors in the SN led to extensive dopaminergic degeneration, in agreement with our recently developed PD mouse model based on AAV-mediated overexpression of untagged WT $\alpha \mathrm{SYN}$ (Oliveras-Salvá et al., 2013). Because loss of transduced dopaminergic neurons in the SN might confound correct interpretation of the BLI signal, the striatum might be the preferential brain region for the evaluation of modulators of $\alpha \mathrm{SYN}$ oligomerization.

To evaluate which $\alpha \mathrm{SYN}$ oligomers contribute to the BLI signal, we applied a cross-linking protocol. Different sizes of oligomers, ranging from dimers to HMW oligomers, were detected both in cell culture and in mouse brain. In cell culture, the BLI signal only arises from $\alpha \mathrm{SYN}$ oligomers because very specific culture conditions (e.g., oxidative stress) are necessary to induce $\alpha \mathrm{SYN}$ to form fibrils. In vivo, interaction between at least two $\alpha \mathrm{SYN}$ molecules results in complementation of Fluc, reflected by the sixfold higher BLI signal when both split- $\alpha$ SYN AAV vectors were injected. However, we cannot judge on the exact type and size of $\alpha \mathrm{SYN}$ oligomers contributing to the signal, nor can we exclude that $\alpha \mathrm{SYN}$ fibrils are partially responsible for the BLI signal in vivo. Nevertheless, one could hypothesize that HMW oligomers and fibrils possess limited luciferase activity due to sterical hindrance resulting in impeded complementation of the two Fluc fragments (Luker et al., 2004; Stynen et al., 2012).

The major asset of noninvasive molecular imaging is that it allows quantitative analysis of a biological process in the same group of animals over time, yielding better quality results from far fewer experimental animals (Massoud and Gambhir, 2003). In both the striatum and the SN, the BLI signal is characterized by an initial increase, followed by a decrease and eventually a stabilization. Interestingly, mice injected with eGFP-T2A-Fluc AAV showed a stable BLI signal from 1 until 4 weeks after injection, indicating that the observed fluctuating kinetics in mice injected with the split-Fluc vectors can be ascribed to $\alpha \mathrm{SYN}$ oligomerization. The initial increase probably reflects a combination of activation of gene expression in all groups, but more importantly, a continuous increase in production of $\alpha \mathrm{SYN}$ oligomers, reflected by the more pronounced increase in BLI signal in the groups injected with two split-Fluc- $\alpha S Y N$ vectors compared with the control groups. The following decrease in BLI signal might be explained by disappearance of transduced cells due to cell death. However, histology revealed a distinct neurodegeneration only in the $\mathrm{SN}$, which might explain the earlier decline in BLI signal in the SN (starting from 1-3 weeks after injection) compared with the striatum (starting from 3-5 weeks after injection). Therefore, another event must be responsible for the decline in BLI signal in the striatum. We hypothesize that the continuous production of oligomers and the conversion of these oligomers into fibrils with limited luciferase activity take place in parallel. Consequently, we suggest that the oligomerization of $\alpha \mathrm{SYN}$ is the predominant process during the initial increase in BLI signal. A threshold is reached between 3 and 5 weeks after injection, after which the conversion into fibrils is the predominant process. The stabilization is then explained by a steady state between these two processes. To verify this hypothesis, one could test artificial mutants that show a strongly reduced formation of amyloid fibrils and a strongly increased propensity to oligomerize (Karpinar et al., 2009; Winner et al., 2011).

We previously showed that FK506 inhibits $\alpha$ SYN fibrillization through the inhibition of FKBP12 (Gerard et al., 2006, 2010). However, one potential risk when inhibiting one step in an aggregation pathway is that accumulation of harmful oligomers could make toxicity worse (Ross and Poirier, 2004). In the present study, we show that FK506 also inhibits oligomerization, both in cell culture and in mouse brain, further validating FKBPs as a drug target for PD and other synucleinopathies (Gerard et al., 
2011). To show a direct link between FKBPs and $\alpha$ SYN oligomerization, nonimmunosuppressive analogs of FK506 or overexpression or knockdown of FKBP12 should be evaluated with our split-Fluc technology. Of note, our finding that FK506 increased the BLI signal after injection with eGFP-T2A-Fluc AAV emphasizes the importance of full-length Fluc as an internal control when evaluating the effect of a small molecule. The immunosuppressive properties of FK506 might have resulted in improved AAV vector transduction in mouse brain, eventually leading to elevated expression levels of Fluc (Ren et al., 2010), although there was no direct evidence of higher transgene expression levels in our experiments. Alternatively, FK506 is known to increase the permeability of the BBB (Kochi et al., 1999; Quezada et al., 2008), which might result in higher availability of D-luciferin and subsequently higher BLI signals.

EGCG can efficiently pass an intact BBB (Suganuma et al., 1998) and has shown neuroprotective effects in animal models of different neurodegenerative diseases (Mandel et al., 2011). Moreover, EGCG inhibits $\alpha$ SYN oligomer and fibril formation in vitro and in cultured cells (Ehrnhoefer et al., 2008; Bieschke et al., 2010; Caruana et al., 2011), but the effect in vivo remained unexplored. In the present study, EGCG did not affect $\alpha$ SYN oligomerization neither in cell culture nor in mouse brain. One possible explanation is that EGCG directly binds to $\alpha$ SYN monomers and remodels them into off-pathway oligomers (Ehrnhoefer et al., 2008; Caruana et al., 2011), which might not be distinguishable from on-pathway oligomers with our split-Fluc technology. Additionally, compared with studies in transgenic Alzheimer's disease mice (Rezai-Zadeh et al., 2005, 2008), our mice received EGCG for a shorter time period and probably have higher protein expression level per cell due to viral transduction. It would therefore still be interesting to test EGCG in $\alpha \mathrm{SYN}$ transgenic mice.

Our bioluminescent PCA opens opportunities for library screening of small-molecule inhibitors of oligomerization in cell culture and validation of identified hits in vivo (Chan et al., 2012; Takakura et al., 2012). Moreover, increasing information supports the notion that prefibrillar oligomers are the main toxic species in different neurological proteinopathies (Ross and Poirier, 2004; Gadad et al., 2011). Our technological approach would allow to study oligomerization of amyloid- $\beta$ (Hashimoto et al., 2011) and tau in Alzheimer's disease, prion protein in Prion's disease, huntingtin in Huntington's disease, or TDP-43 in amyotrophic lateral sclerosis.

In conclusion, we report a new powerful technique that allows to visualize $\alpha \mathrm{SYN}$ oligomers in cell culture and in mouse brain. The value of this technology is evidenced by its use to provide new insights into the role of small molecules on $\alpha \mathrm{SYN}$ oligomerization. More specifically, we have demonstrated that the FKBP inhibitor FK506 reduces $\alpha$ SYN oligomerization in cell culture and in mouse brain. This technique opens new perspectives in the quest for neuroprotective therapies for PD and other synucleinopathies.

\section{References}

Anderson JP, Walker DE, Goldstein JM, de Laat R, Banducci K, Caccavello RJ, Barbour R, Huang J, Kling K, Lee M, Diep L, Keim PS, Shen X, Chataway T, Schlossmacher MG, Seubert P, Schenk D, Sinha S, Gai WP, Chilcote TJ (2006) Phosphorylation of Ser-129 is the dominant pathological modification of $\alpha$-synuclein in familial and sporadic Lewy body disease. J Biol Chem 281:29739-29752. CrossRef Medline

Baekelandt V, Claeys A, Eggermont K, Lauwers E, De Strooper B, Nuttin B, Debyser Z (2002) Characterization of lentiviral vector-mediated gene transfer in adult mouse brain. Hum Gene Ther 13:841-853. CrossRef Medline

Bartels T, Choi JG, Selkoe DJ (2011) $\alpha$-Synuclein occurs physiologically as a helically folded tetramer that resists aggregation. Nature 477:107-110. CrossRef Medline

Bieschke J, Russ J, Friedrich RP, Ehrnhoefer DE, Wobst H, Neugebauer K, Wanker EE (2010) EGCG remodels mature $\alpha$-synuclein and amyloid- $\beta$ fibrils and reduces cellular toxicity. Proc Natl Acad Sci U S A 107:77107715. CrossRef Medline

Binolfi A, Theillet FX, Selenko P (2012) Bacterial in-cell NMR of human $\alpha$-synuclein: a disordered monomer by nature? Biochem Soc Trans 40: 950-954. CrossRef Medline

Burré J, Vivona S, Diao J, Sharma M, Brunger AT, Südhof TC (2013) Properties of native brain $\alpha$-synuclein. Nature 498:E4-E6; discussion E6-E7. CrossRef Medline

Caruana M, Högen T, Levin J, Hillmer A, Giese A, Vassallo N (2011) Inhibition and disaggregation of $\alpha$-synuclein oligomers by natural polyphenolic compounds. FEBS Lett 585:1113-1120. CrossRef Medline

Chan CT, Reeves RE, Geller R, Yaghoubi SS, Hoehne A, Solow-Cordero DE, Chiosis G, Massoud TF, Paulmurugan R, Gambhir SS (2012) Discovery and validation of small-molecule heat-shock protein 90 inhibitors through multimodality molecular imaging in living subjects. Proc Natl Acad Sci U S A 109:E2476-E2485. CrossRef Medline

Colla E, Jensen PH, Pletnikova O, Troncoso JC, Glabe C, Lee MK (2012) Accumulation of toxic $\alpha$-synuclein oligomer within endoplasmic reticulum occurs in $\alpha$-synucleinopathy in vivo. J Neurosci 32:3301-3305. CrossRef Medline

Czupryna J, Tsourkas A (2011) Firefly luciferase and Rluc8 exhibit differential sensitivity to oxidative stress in apoptotic cells. PLoS One 6:e20073. CrossRef Medline

Danzer KM, Ruf WP, Putcha P, Joyner D, Hashimoto T, Glabe C, Hyman BT, McLean PJ (2011) Heat-shock protein 70 modulates toxic extracellular $\alpha$-synuclein oligomers and rescues trans-synaptic toxicity. FASEB J 25 : 326-336. CrossRef Medline

Danzer KM, Kranich LR, Ruf WP, Cagsal-Getkin O, Winslow AR, Zhu L, Vanderburg CR, McLean PJ (2012) Exosomal cell-to-cell transmission of alpha synuclein oligomers. Mol Neurodegener 7:42. CrossRef Medline

Davidson WS, Jonas A, Clayton DF, George JM (1998) Stabilization of alpha-synuclein secondary structure upon binding to synthetic membranes. J Biol Chem 273:9443-9449. CrossRef Medline

Deleersnijder A, Van Rompuy AS, Desender L, Pottel H, Buée L, Debyser Z, Baekelandt V, Gerard M (2011) Comparative analysis of different peptidyl-prolyl isomerases reveals FK506-binding protein 12 as the most potent enhancer of alpha-synuclein aggregation. J Biol Chem 286:2668726701. CrossRef Medline

Deleersnijder A, Gerard M, Debyser Z, Baekelandt V (2013) The remarkable conformational plasticity of alpha-synuclein: blessing or curse? Trends Mol Med 19:368-377. CrossRef Medline

Deroose CM, Reumers V, Gijsbers R, Bormans G, Debyser Z, Mortelmans L, Baekelandt V (2006) Noninvasive monitoring of long-term lentiviral vector-mediated gene expression in rodent brain with bioluminescence imaging. Mol Ther 14:423-431. CrossRef Medline

Deroose CM, Reumers V, Debyser Z, Baekelandt V (2009) Seeing genes at work in the living brain with non-invasive molecular imaging. Curr Gene Ther 9:212-238. CrossRef Medline

Dettmer U, Newman AJ, Luth ES, Bartels T, Selkoe D (2013) In vivo crosslinking reveals principally oligomeric forms of $\alpha$-synuclein and $\beta$-synuclein in neurons and non-neural cells. J Biol Chem 288:63716385. CrossRef Medline

Dimant H, Kalia SK, Kalia LV, Zhu LN, Kibuuka L, Ebrahimi-Fakhari D, McFarland NR, Fan Z, Hyman BT, McLean PJ (2013) Direct detection of alpha synuclein oligomers in vivo. Acta Neuropathol Commun 1:6. CrossRef Medline

Ehrnhoefer DE, Bieschke J, Boeddrich A, Herbst M, Masino L, Lurz R, Engemann S, Pastore A, Wanker EE (2008) EGCG redirects amyloidogenic polypeptides into unstructured, off-pathway oligomers. Nat Struct Mol Biol 15:558-566. CrossRef Medline

Fagerqvist T, Lindström V, Nordström E, Lord A, Tucker SM, Su X, Sahlin C, Kasrayan A, Andersson J, Welander H, Näsström T, Holmquist M, Schell H, Kahle PJ, Kalimo H, Möller C, Gellerfors P, Lannfelt L, Bergström J, Ingelsson M (2013) Monoclonal antibodies selective for $\alpha$-synuclein oligomers/protofibrils recognize brain pathology in Lewy body disorders and $\alpha$-synuclein transgenic mice with the disease-causing A30P mutation. J Neurochem 126:131-144. CrossRef Medline

Fauvet B, Mbefo MK, Fares MB, Desobry C, Michael S, Ardah MT, Tsika E, 
Coune P, Prudent M, Lion N, Eliezer D, Moore DJ, Schneider B, Aebischer P, El-Agnaf OM, Masliah E, Lashuel HA (2012) Alpha-synuclein in the central nervous system and from erythrocytes, mammalian cells and E. coli exists predominantly as a disordered monomer. J Biol Chem 287:15345-15364. CrossRef Medline

Gadad BS, Britton GB, Rao KS (2011) Targeting oligomers in neurodegenerative disorders: lessons from $\alpha$-synuclein, tau, and amyloid- $\beta$ peptide. J Alzheimers Dis 24 [Suppl 2]:223-232.

Gerard M, Debyser Z, Desender L, Kahle PJ, Baert J, Baekelandt V, Engelborghs Y (2006) The aggregation of alpha-synuclein is stimulated by FK506 binding proteins as shown by fluorescence correlation spectroscopy. FASEB J 20:524-526. CrossRef Medline

Gerard M, Deleersnijder A, Daniëls V, Schreurs S, Munck S, Reumers V, Pottel H, Engelborghs Y, Van den Haute C, Taymans JM, Debyser Z, Baekelandt V (2010) Inhibition of FK506 binding proteins reduces alpha-synuclein aggregation and Parkinson's disease-like pathology. J Neurosci 30:2454-2463. CrossRef Medline

Gerard M, Deleersnijder A, Demeulemeester J, Debyser Z, Baekelandt V (2011) Unraveling the role of peptidyl-prolyl isomerases in neurodegeneration. Mol Neurobiol 44:13-27. CrossRef Medline

Halliday GM, Holton JL, Revesz T, Dickson DW (2011) Neuropathology underlying clinical variability in patients with synucleinopathies. Acta Neuropathol (Berl) 122:187-204. CrossRef Medline

Hashimoto T, Adams KW, Fan Z, McLean PJ, Hyman BT (2011) Characterization of oligomer formation of amyloid-peptide using a splitluciferase complementation assay. J Biol Chem 286:27081-27091. CrossRef Medline

Heeman B, Van den Haute C, Aelvoet SA, Valsecchi F, Rodenburg RJ, Reumers V, Debyser Z, Callewaert G, Koopman WJ, Willems PH, Baekelandt V (2011) Depletion of PINK1 affects mitochondrial metabolism, calcium homeostasis and energy maintenance. J Cell Sci 124:1115-1125. CrossRef Medline

Hong HS, Hwang JY, Son SM, Kim YH, Moon M, Inhee MJ (2010) FK506 reduces amyloid plaque burden and induces MMP-9 in A $\beta$ PP/PS1 double transgenic mice. J Alzheimers Dis 22:97-105. CrossRef Medline

Ibrahimi A, Vande Velde G, Reumers V, Toelen J, Thiry I, Vandeputte C, Deroose C, Bormans G, Baekelandt V, Debyser Z, Gijsbers R (2009) Highly efficient multicistronic lentiviral vectors with peptide $2 \mathrm{~A}$ sequences. Hum Gene Ther 20:845-860. CrossRef Medline

Kahle PJ, Neumann M, Ozmen L, Müller V, Jacobsen H, Schindzielorz A, Okochi M, Leimer U, Putten H van der, Probst A, Kremmer E, Kretzschmar HA, Haass C (2000) Subcellular localization of wild-type and Parkinson's disease-associated mutant $\alpha$-synuclein in human and transgenic mouse brain. J Neurosci 20:6365-6373. Medline

Kalia LV, Kalia SK, McLean PJ, Lozano AM, Lang AE (2013) $\alpha$-Synuclein oligomers and clinical implications for Parkinson disease. Ann Neurol 73:155-169. CrossRef Medline

Karpinar DP, Balija MB, Kügler S, Opazo F, Rezaei-Ghaleh N, Wender N, Kim HY, Taschenberger G, Falkenburger BH, Heise H, Kumar A, Riedel D, Fichtner L, Voigt A, Braus GH, Giller K, Becker S, Herzig A, Baldus M, Jäckle H, et al (2009) Pre-fibrillar $\alpha$-synuclein variants with impaired $\beta$-structure increase neurotoxicity in Parkinson's disease models. EMBO J 28:3256-3268. CrossRef Medline

Kayed R, Head E, Thompson JL, McIntire TM, Milton SC, Cotman CW, Glabe CG (2003) Common structure of soluble amyloid oligomers implies common mechanism of pathogenesis. Science 300:486-489. CrossRef Medline

Kochi S, Takanaga H, Matsuo H, Naito M, Tsuruo T, Sawada Y (1999) Effect of cyclosporin A or tacrolimus on the function of blood-brain barrier cells. Eur J Pharmacol 372:287-295. CrossRef Medline

Kuzuhara S, Mori H, Izumiyama N, Yoshimura M, Ihara Y (1988) Lewy bodies are ubiquitinated. Acta Neuropathol (Berl) 75:345-353. CrossRef Medline

Lee BR, Kamitani T (2011) Improved immunodetection of endogenous $\alpha$-synuclein. PLoS One 6:e23939. CrossRef Medline

Leng W, Pang X, Xia H, Li M, Chen L, Tang Q, Yuan D, Li R, Li L, Gao F, Bi F (2013) Novel split-luciferase-based genetically encoded biosensors for noninvasive visualization of Rho GTPases. PLoS One 8:e62230. CrossRef Medline

Lindersson E, Beedholm R, Højrup P, Moos T, Gai W, Hendil KB, Jensen PH (2004) Proteasomal inhibition by $\alpha$-synuclein filaments and oligomers. J Biol Chem 279:12924-12934. CrossRef Medline
Luker KE, Smith MC, Luker GD, Gammon ST, Piwnica-Worms H, PiwnicaWorms D (2004) Kinetics of regulated protein-protein interactions revealed with firefly luciferase complementation imaging in cells and living animals. Proc Natl Acad Sci U S A 101:12288-12293. CrossRef Medline

Luker KE, Mihalko LA, Schmidt BT, Lewin SA, Ray P, Shcherbo D, Chudakov DM, Luker GD (2011) In vivo imaging of ligand receptor binding with Gaussia luciferase complementation. Nat Med 18:172-177. CrossRef Medline

Mandel SA, Amit T, Weinreb O, Youdim MB (2011) Understanding the broad-spectrum neuroprotective action profile of green tea polyphenols in aging and neurodegenerative diseases. J Alzheimers Dis 25:187-208. CrossRef Medline

Massoud TF, Gambhir SS (2003) Molecular imaging in living subjects: seeing fundamental biological processes in a new light. Genes Dev 17:545580. CrossRef Medline

Massoud TF, Singh A, Gambhir SS (2008) Noninvasive molecular neuroimaging using reporter genes: II. Experimental, current, and future applications. Am J Neuroradiol 29:409-418. CrossRef Medline

Meuvis J, Gerard M, Desender L, Baekelandt V, Engelborghs Y (2010) The conformation and the aggregation kinetics of $\alpha$-synuclein depend on the proline residues in its C-terminal region. Biochemistry (Mosc) 49:93459352. CrossRef Medline

Newman AJ, Selkoe D, Dettmer U (2013) A new method for quantitative immunoblotting of endogenous $\alpha$-synuclein. PLoS One 8:e81314. CrossRef Medline

Oliveras-Salvá M, Van der Perren A, Casadei N, Stroobants S, Nuber S, D'Hooge R, Van den Haute C, Baekelandt V (2013) rAAV2/7 vectormediated overexpression of alpha-synuclein in mouse substantia nigra induces protein aggregation and progressive dose-dependent neurodegeneration. Mol Neurodegener 8:44. CrossRef Medline

Ostrerova-Golts N, Petrucelli L, Hardy J, Lee JM, Farer M, Wolozin B (2000) The A53T $\alpha$-synuclein mutation increases iron-dependent aggregation and toxicity. J Neurosci 20:6048-6054. Medline

Outeiro TF, Putcha P, Tetzlaff JE, Spoelgen R, Koker M, Carvalho F, Hyman BT, McLean PJ (2008) Formation of toxic oligomeric $\alpha$-synuclein species in living cells. PLoS One 3:e1867. CrossRef Medline

Paleologou KE, Kragh CL, Mann DM, Salem SA, Al-Shami R, Allsop D, Hassan AH, Jensen PH, El-Agnaf OMA (2009) Detection of elevated levels of soluble $\alpha$-synuclein oligomers in post-mortem brain extracts from patients with dementia with Lewy bodies. Brain 132:1093-1101. CrossRef Medline

Paulmurugan R, Gambhir SS (2007) Combinatorial library screening for developing an improved split-firefly luciferase fragment-assisted complementation system for studying protein-protein interactions. Anal Chem 79:2346-2353. CrossRef Medline

Paulmurugan R, Umezawa Y, Gambhir SS (2002) Noninvasive imaging of protein-protein interactions in living subjects by using reporter protein complementation and reconstitution strategies. Proc Natl Acad Sci U S A 99:15608-15613. CrossRef Medline

Pichler A, Prior JL, Piwnica-Worms D (2004) Imaging reversal of multidrug resistance in living mice with bioluminescence: MDR1 P-glycoprotein transports coelenterazine. Proc Natl Acad Sci U S A 101:1702-1707. CrossRef Medline

Putcha P, Danzer KM, Kranich LR, Scott A, Silinski M, Mabbett S, Hicks CD, Veal JM, Steed PM, Hyman BT, McLean PJ (2010) Brain-permeable small-molecule inhibitors of $\mathrm{Hsp} 90$ prevent $\alpha$-synuclein oligomer formation and rescue $\alpha$-synuclein-induced toxicity. J Pharmacol Exp Ther 332: 849-857. CrossRef Medline

Quezada CA, Garrido WX, González-Oyarzun MA, Rauch MC, Salas MR, San Martín RE, Claude AA, Yañez AJ, Slebe JC, Cárcamo JG (2008) Effect of tacrolimus on activity and expression of P-glycoprotein and ATPbinding cassette transporter A5 (ABCA5) proteins in hematoencephalic barrier cells. Biol Pharm Bull 31:1911-1916. CrossRef Medline

Ren X, Zhang T, Hu J, Ding W, Wang X (2010) Triptolide T10 enhances AAV-mediated gene transfer in mice striatum. Neurosci Lett 479:187191. CrossRef Medline

Reumers V, Deroose CM, Krylyshkina O, Nuyts J, Geraerts M, Mortelmans L, Gijsbers R, Van den Haute C, Debyser Z, Baekelandt V (2008) Noninvasive and quantitative monitoring of adult neuronal stem cell migration in mouse brain using bioluminescence imaging. Stem Cells 26:23822390. CrossRef Medline

Rezai-Zadeh K, Shytle D, Sun N, Mori T, Hou H, Jeanniton D, Ehrhart J, 
Townsend K, Zeng J, Morgan D, Hardy J, Town T, Tan J (2005) Green tea epigallocatechin-3-gallate (EGCG) modulates amyloid precursor protein cleavage and reduces cerebral amyloidosis in Alzheimer transgenic mice. J Neurosci 25:8807-8814. CrossRef Medline

Rezai-Zadeh K, Arendash GW, Hou H, Fernandez F, Jensen M, Runfeldt M, Shytle $\mathrm{RD}$, Tan J (2008) Green tea epigallocatechin-3-gallate (EGCG) reduces $\beta$-amyloid mediated cognitive impairment and modulates tau pathology in Alzheimer transgenic mice. Brain Res 1214:177-187. CrossRef Medline

Ross CA, Poirier MA (2004) Protein aggregation and neurodegenerative disease. Nat Med 10 [Suppl]:S10-S17.

Sharon R, Bar-Joseph I, Frosch MP, Walsh DM, Hamilton JA, Selkoe DJ (2003) The formation of highly soluble oligomers of $\alpha$-synuclein is regulated by fatty tcids and enhanced in Parkinson's disease. Neuron 37:583595. CrossRef Medline

Spillantini MG, Schmidt ML, Lee VM, Trojanowski JQ, Jakes R, Goedert M (1997) alpha-Synuclein in Lewy bodies. Nature 388:839-840. CrossRef Medline

Stynen B, Tournu H, Tavernier J, Van Dijck P (2012) Diversity in genetic in vivo methods for protein-protein interaction studies: from the yeast twohybrid system to the mammalian split-luciferase system. Microbiol Mol Biol Rev 76:331-382. CrossRef Medline

Suganuma M, Okabe S, Oniyama M, Tada Y, Ito H, Fujiki H (1998) Wide distribution of $\left[{ }^{3} \mathrm{H}\right](-)$-epigallocatechin gallate, a cancer preventive tea polyphenol, in mouse tissue. Carcinogenesis 19:1771-1776. CrossRef Medline

Takakura H, Hattori M, Takeuchi M, Ozawa T (2012) Visualization and quantitative analysis of $\mathrm{G}$ protein-coupled receptor- $\beta$-arrestin interaction in single cells and specific organs of living mice using split luciferase complementation. ACS Chem Biol 7:901-910. CrossRef Medline

Tofaris GK, Razzaq A, Ghetti B, Lilley KS, Spillantini MG (2003) Ubiquitination of $\alpha$-synuclein in Lewy bodies is a pathological event not associated with impairment of proteasome function. J Biol Chem 278: 44405-44411. CrossRef Medline
Van der Perren A, Toelen J, Carlon M, Van den Haute C, Coun F, Heeman B, Reumers V, Vandenberghe LH, Wilson JM, Debyser Z, Baekelandt V (2011) Efficient and stable transduction of dopaminergic neurons in rat substantia nigra by rAAV $2 / 1,2 / 2,2 / 5,2 / 6.2,2 / 7,2 / 8$ and $2 / 9$. Gene Ther 18:517-527. CrossRef Medline

Vandeputte C, Reumers V, Aelvoet SA, Thiry I, De Swaef S, Van den Haute C, Pascual-Brazo J, Farr TD, Vande Velde G, Hoehn M, Himmelreich U, Van Laere K, Debyser Z, Gijsbers R, Baekelandt V (2014) Bioluminescence imaging of stroke-induced endogenous neural stem cell response. Neurobiol Dis 69:144-155. CrossRef Medline

Vercammen L, Van der Perren A, Vaudano E, Gijsbers R, Debyser Z, Van den Haute C, Baekelandt V (2006) Parkin protects against neurotoxicity in the 6-hydroxydopamine rat model for Parkinson's disease. Mol Ther 14: 716-723. CrossRef Medline

Wang W, Perovic I, Chittuluru J, Kaganovich A, Nguyen LT, Liao J, Auclair JR, Johnson D, Landeru A, Simorellis AK, Ju S, Cookson MR, Asturias FJ, Agar JN, Webb BN, Kang C, Ringe D, Petsko GA, Pochapsky TC, Hoang QQ (2011) A soluble $\alpha$-synuclein construct forms a dynamic tetramer. Proc Natl Acad Sci U S A 108:17797-17802. CrossRef Medline

Wang Y, Li M, Xu X, Song M, Tao H, Bai Y (2012) Green tea epigallocatechin-3-gallate (EGCG) promotes neural progenitor cell proliferation and sonic hedgehog pathway activation during adult hippocampal neurogenesis. Mol Nutr Food Res 56:1292-1303. CrossRef Medline

Winner B, Jappelli R, Maji SK, Desplats PA, Boyer L, Aigner S, Hetzer C, Loher T, Vilar M, Campioni S, Tzitzilonis C, Soragni A, Jessberger S, Mira H, Consiglio A, Pham E, Masliah E, Gage FH, Riek R (2011) In vivo demonstration that $\alpha$-synuclein oligomers are toxic. Proc Natl Acad Sci U S A 108:4194-4199. CrossRef Medline

Zhao H, Doyle TC, Coquoz O, Kalish F, Rice BW, Contag CH (2005) Emission spectra of bioluminescent reporters and interaction with mammalian tissue determine the sensitivity of detection in vivo. J Biomed Opt 10:041210-041219. CrossRef Medline 